\title{
WAGNER MALAGó TAVARES
}

\section{Avaliação de protocolo para redução da distorção em estereotaxia para ressonância magnética de três tesla}

Tese apresentada à Faculdade de Medicina da Universidade de São Paulo para obtenção do título de Doutor em Ciências

Programa de Neurologia

Orientador: Prof. Dr. Erich Talamoni Fonoff 
Dados Internacionais de Catalogação na Publicação (CIP)

Preparada pela Biblioteca da

Faculdade de Medicina da Universidade de São Paulo

Creprodução autorizada pelo autor

Tavares, Wagner Malagó

Avaliação de protocolo para redução da distorção em estereotaxia para ressonância magnética de três tesla / Wagner Malagó Tavares. -- São Paulo, 2015.

Tese(doutorado)--Faculdade de Medicina da Universidade de São Paulo. Programa de Neurologia.

Orientador: Erich Talamoni Fonoff.

Descritores: 1.Neurocirurgia 2.Processamento de imagem assistida por computador/métodos 3.Imagens de fantasmas 4.Radiocirurgia 5.Algoritmos

USP/FM/DBD-310/15 
"I am wiser than this man, for neither of us appears to know anything great and good; but he fancies he knows something, although he knows nothing; whereas I, as I do not know anything, so I do not fancy I do. In this trifling particular, then, I appear to be wiser than he, because I do not fancy I know what I do not know."

Socnates, Apalogia, 399 a. . 
Carol, Renan, João Pedro, Mateus, Vanda e Tavares

Pela dedicação, paciência, apoio e amor incondicional 


\section{AGRADECIMENTOS}

Ao Prof. Dr. Manoel Jacobsen Teixeira, pelas oportunidades oferecidas e experiência proporcionada.

Ao Dr. Erich Talamoni Fonoff, pela dedicação, incentivo e orientação nesta jornada.

À Profa. Dra. Cláudia da Costa Leite, pela constante apoio e disponibilidade para as necessidades da Divisão de Neurocirurgia Funcional.

Ao Prof. Dr. Edson Amaro Jr., por clarear o caminho a ser percorrido.

Ao Dr. Lionel Gamarra, que através da dedicação ao projeto e ao aluno permitiu a concretização do protocolo.

Aos pacientes, que sempre colaboraram de maneira prestativa e harmoniosa. 
Esta tese está de acordo com as seguintes normas, em vigor no momento desta publicação:

Referências: adaptado de International Committee of Medical Journals Editors (Vancouver).

Universidade de São Paulo. Faculdade de Medicina. Serviço de Biblioteca e Documentação. Guia de apresentação de dissertações, teses e monografias.

Elaborado por Anneliese Carneiro da Cunha, Maria Julia de A. L. Freddi, Maria F. Crestana, Marinalva de Souza Aragão, Suely Campos Cardoso, Valéria Vilhena. $3^{\mathrm{a}}$ ed. São Paulo: Divisão de Biblioteca e Documentações; 2011.

Abreviatura dos títulos dos periódicos de acordo com List of Journals Indexed in Index Medicus. 


\section{SUMÁRIO}

Lista de abreviaturas e siglas

Lista de figuras

Lista de tabelas

Resumo

Abstract

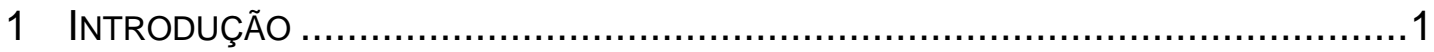

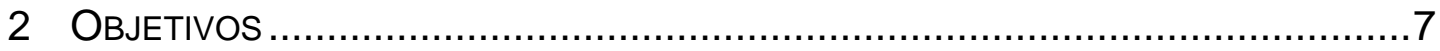

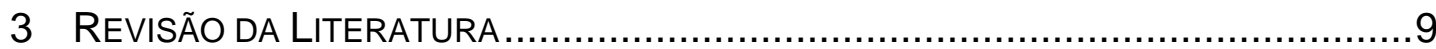

3.1 Princípios da Estereotaxia ........................................................ 10

3.2 RM com Magneto de Alta Potência ................................................. 17

3.3 O Problema da Distorção ..........................................................19

3.3.1 Não linearidade do campo magnético .......................................20

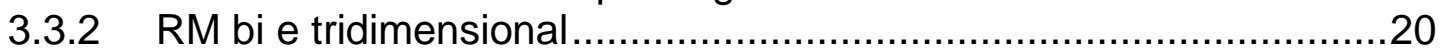

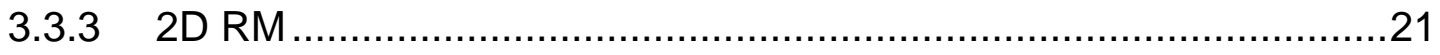

3.3.4 Ressonância de Aquisição Tridimensional (RM 3D) .......................22

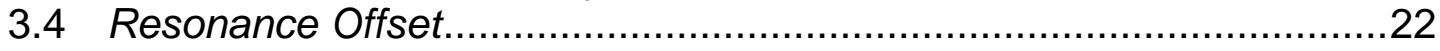

3.4.1 Deslocamento Químico (Chemical Shifts)...................................23

3.4.2 Heterogeneidade do Campo Magnético ......................................24

3.4.3 Distorção induzida pelo aparelho de ressonância magnética ..........24

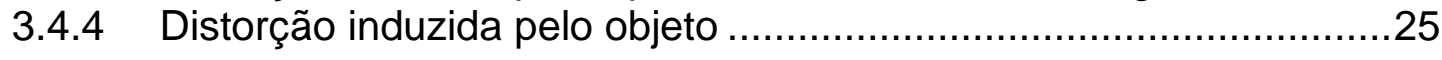

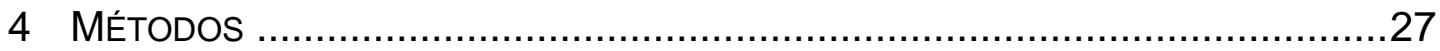

4.1. Modelo Tridimensional com Alvos para Estudo da Distorção e Halo Estereotáctico ..................................................................28

4.2 Modelo Matemático para Cálculo e Correção da Distorção ..................30

4.3 Seleção de Doentes ..................................................................... 35

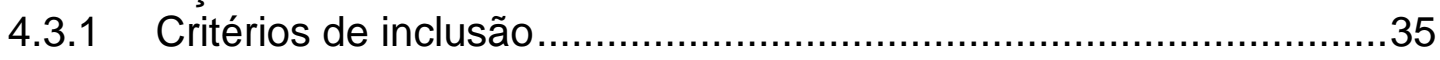

4.3.2 Critérios de exclusão...........................................................36

4.3.3 Procedimentos de aquisição de imagens de CT e RM dos pacientes incluídos no estudo ....................................................36

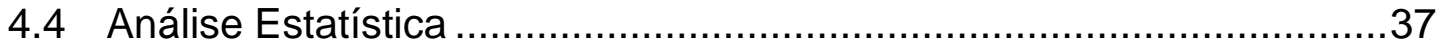

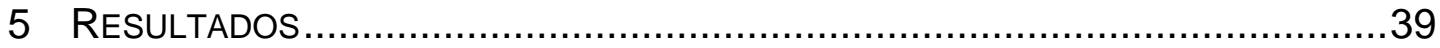

5.1 Análise da Distorção e Correção no MTA ….......................................40

5.2 ANÁLISE da Distorção e Correção em Doentes ................................43

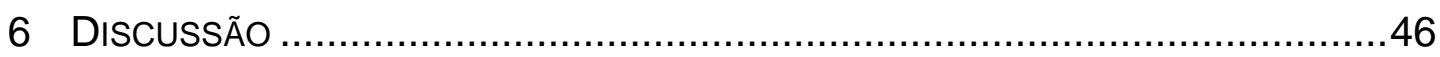

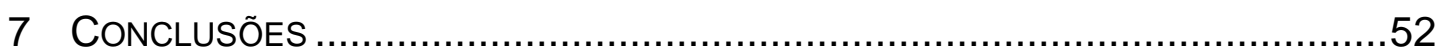

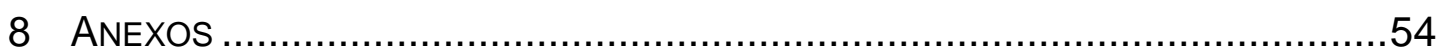

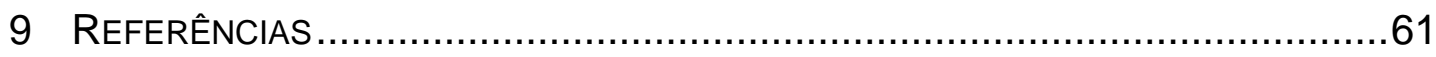

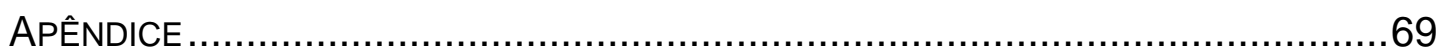




\section{LISTA DE ABREVIATURAS SÍMBOLOS E SIGLAS}

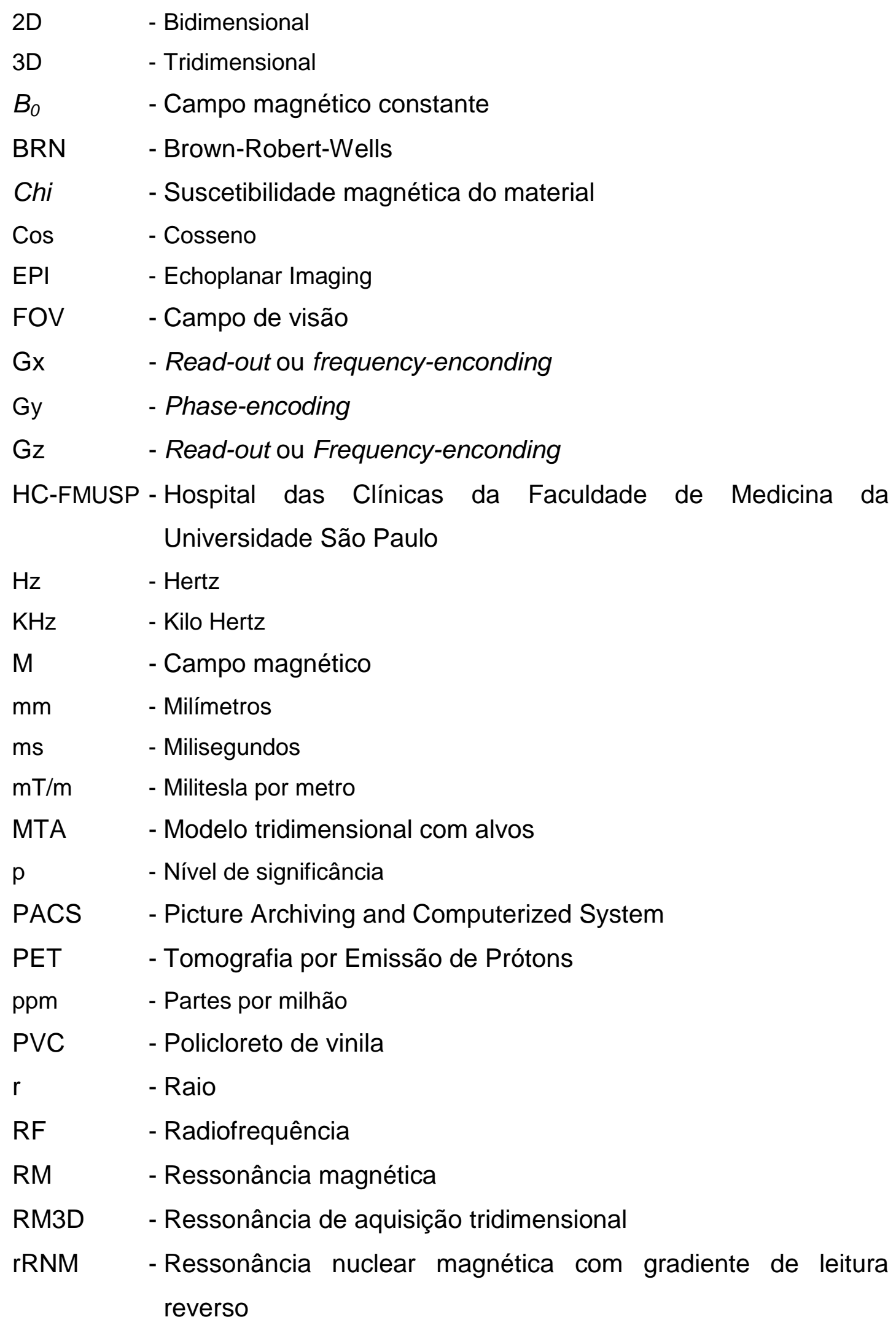
reverso 


$\begin{array}{ll}\text { RSR } & \text { - Relação sinal-ruído } \\ \text { SAR } & \text { - Taxa de absorção específica } \\ \text { Sen } & \text { - Seno } \\ \text { SNR } & \text { - Razão sinal-ruído } \\ \text { SPECT } & \text { - Tomografia Computadorizada por Emissão de Fóton Único } \\ \text { T } & \text { - Tesla } \\ \text { T1 } & \text { - Tempo de relaxamento longitudinal } \\ \text { TC } & \text { - Tomografia Computadorizada } \\ \text { TE } & \text { - Tempo echo } \\ \text { TM } & \text { - Teixeira-Matos } \\ \text { TR } & \text { - Tempo de repetição } \\ ( & - \text { Teta } \\ 7 & \text { - Omega }\end{array}$




\section{LISTA DE FIGURAS}

Figura 1 - Os três eixos cartesianos "x", "y" e "z" e a intersecção em

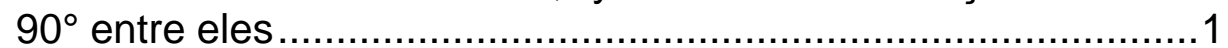

Figura 2 - Gráfico da sequência de RM normal e reversa. Note a inversão da primeira linha que se refere ao gradiente de leitura.

Figura 3 - Corte axial do MTA com os pontos A, B, C e D identificáveis

Figura 4 - Aquisição nRM (a), rRM (b) e subtração das imagens demonstrando a distorção geométrica no eixo do gradiente de leitura 


\section{LISTA DE TABELAS}

Tabela 1 - Coeficiente de Cronbach para consistência dos dados .40

Tabela 2 - Valores médios para os três pontos marcados por cada voluntário (pontos iguais para todos os voluntários) utilizando tomografia computadorizada.

Tabela 3 -Valores médios para os três pontos da RM após a correção da imagem

Tabela 4 - Dados totais obtidos da coordenada $\mathrm{x}$ para cada tipo de aquisição de imagem, ponto escolhido e voluntário.

Tabela 5 - Diferença entre as coordenadas obtidos na TC e as obtidas após a correção. 


\section{RESUMO}

Tavares WM. Avaliação de protocolo para redução da distorção em estereotaxia para ressonância magnética de três tesla [tese]. São Paulo: Faculdade de Medicina, Universidade de São Paulo; 2015.

Introdução: o presente estudo demonstra a aplicação de um algoritmo para correção de distorções em imagens de RM em 3T. Métodos: foi utilizado um Modelo Tridimensional com Alvos (MTA) de acrílico (Micromar, São Paulo, Brasil) montado em uma plataforma com as dimensões e características de um arco estereotáctico. O MTA foi submetido à aquisição de imagens em uma bobina de crânio utilizando o aparelho Philips 3T Magnetom Sigma LX ${ }^{\mathrm{TM}}$ (Philips Medical Systems, Eindhoven, Netherlands). Para cada aquisição duas imagens foram obtidas, a normal e a reversa (nRM e rRM, respectivamente). Foi aplicado o protocolo de correção com gradiente reverso para produzir coordenadas $\mathrm{x}$, y e $\mathrm{z}$ corrigidas. Após ter sido determinada a acurácia dos alvos, foram submetidos 20 pacientes ao mesmo protocolo para determinar a validade em indivíduos. Resultados: a análise dos dados demonstrou que as diferenças entre observadores não foram estatisticamente significantes. Além disso, os pontos obtidos após o processo de retificação das coordenadas no MTA revelou uma distorção média de 1,05 mm. Nos pacientes, a distorção pré correção variava de 0 a 5,6 mm; após a correção variou entre 0 e 3,5 mm. Conclusão: o presente estudo examinou uma técnica de retificação das distorções geométricas encontradas em imagens de RM. Esta mostrou-se bem sucedida em produzir resultados consistentemente acurados para registro de alvos estereotácticos. A técnica pode ser aplicada de maneira universal a todas as imagens de RM adquiridas em protocolo spin-echo e corrige as distorções geométricas presentes.

Descritores: Neurocirurgia. Processamento de imagem assistida por computador. Imagens de fantasmas. Radiocirurgia. Algoritmos. 


\begin{abstract}
Tavares WM. A method for geometric distortion correction for stereotaxic neurosurgery on three tesla [thesis]. São Paulo: "Faculdade de Medicina, Universidade de São Paulo"; 2015.

The present work presents an application of a image distortion correction algorithm for 3T MR images. Methods: We used a phantom head model (Micromar, São Paulo, Brazil) mounted on a plataform with the dimensions and features of a stereotactic frame. The phantom was scanned within the head coil of a Philips 3T Magnetom Sigma LXTM (Philips Medical Systems, Eindhoven, Netherlands). For each scan, 2 images were obtained - the normal and the reversed image (nMR and rMR, respectively). We applied the inverted gradient correction protocol to produce a corrected $\mathrm{x}, \mathrm{y}$ and $\mathrm{z}$ coordinate. After we ensure target accuracy we submitted 20 patients to the same protocol to exactitude evaluation in human subjects. Results: For all the analyzed data, the differences among the observers were not statistically significant. Moreover, the data rectification proved to be effective as the average distortion on phantom, after correction, was $1.05 \mathrm{~mm}$. On patients the pre-correction distortion varied between 0 and $5.6 \mathrm{~mm}$, after correction it varied between $0 \mathrm{~mm}$ and $3.5 \mathrm{~mm}$. Conclusion: This study examined a rectifying technique for correcting geometric distortions encountered in the MR images, and the technique proved to be highly successful in producing consistently accurate stereotactic target registration. The technique is universally applicable to all routinely employed spin-echo MR images, and corrects for geometric distortions.
\end{abstract}

Descriptors: Neurosurgery. Image processing. Computer-assisted. phantoms. Imaging. Radiosurgery. Algorithms. 
1 INTRODUÇÃO 
O desenvolvimento da Ressonância Magnética (RM) permitiu a caracterização da imagem tecidual com maior riqueza de detalhes o que aumentou a sensibilidade deste método, principalmente o que concerne à avaliação do sistema nervoso. A aplicação da RM ao método estereotáctico aumentou a precisão na orientação de procedimentos com fins diagnósticos e terapêuticos. Entretanto, há distorções geométricas geradas pelo aparelho de RM e pelos componentes dos tecidos do doente a ser estudado por meio da imagem. Com isso, ainda há dúvidas se os alvos encefálicos poderiam ser determinados diretamente na imagem da RM, aplicando-os à procedimentos neurocirúrgicos funcionais e radioterápicos guiados por imagem. Existem diversas descrições sobre a distorção intrínseca e os respectivos métodos para sua correção, entanto, existem poucas evidências que esses métodos tenham permeado a prática clínica. Além disso, com a maior disponibilidade de magnetos de alto campo com configurações de gradientes curtas e rápidas, é de se esperar que a distorção de imagem torne-se uma questão cada vez mais importante. Com isso, foi proposto a quantificação da distorção e sequencialmente investigar métodos para sua correção em RM de $3 \mathrm{~T}$ visando a utilização direta em procedimentos esterotácticos. Tais procedimentos terapêuticos exigem acurácia espacial para identificação e delineação adequada de alvos milimétricos que se traduzem em resultados clínicos dos tratamentos empregados. 
A imagem em ambiente de RM permite a visibilização da estrutura do encéfalo em maior detalhe, todavia, a acurácia geométrica dessas imagens é limitada pela homogeneidade do campo $B_{0}$, a linearidade dos gradientes aplicados, a susceptibilidade dos tecidos e os artefatos de chemical shift. A reconstrução da imagem em RM parte do pressuposto que o campo $B_{0}$ e a linearidade dos gradientes são perfeitos. No entanto, linearidade é limitada por vários fatores que dependem da conformação do aparelho. Exemplo disso são os aparelhos de RM que apresentam maior diâmetro e por isso são preferidos pelos doentes por ser mais confortáveis. Deste modo, invariavelmente tais características podem comprometem a homogeneidade do $B_{0}$ adicionando fontes de distorção. Além disso, gradientes rápidos e de alto desempenho, especialmente os que empregam bobinas curtas, frequentemente sofrem aumento da não linearidade do gradiente (Wang et al., 2004a).

Diferenças entre o campo magnético esperado e o real, em cada ponto no diâmetro do magneto, levam a distorções durante e geração das imagens. A magnitude e a direção da distorção geométrica variam para cada tipo de protocolo de imagem utilizado e pode chegar a $25 \mathrm{~mm}$ dentro do campo de visão de $24 \mathrm{~cm}$ em magnetos de 1,5T (Wang et al., 2004a, Doran et al., 2005). Embora erros geométricos de magnitude milimétrica não sejam problemáticos para propósitos diagnósticos, os métodos intervencionistas em neurocirurgia estereotáctica funcional e radioterapêuticos necessitam de acurácia de até $1 \mathrm{~mm}$ (Doran et al., 2005; Bakker et al., 1992). Tais procedimentos são realizados por meio de imagens de tomografia computadorizada (TC), devido à acurácia espacial superior na RM. Porém, a 
resolução tecidual é significativamente menor quando comparada à $R M$, tornando difícil a delineação precisa de estruturas anatômicas, principalmente as intraparenquimatosas. Além da definição tecidual superior da RM, esta proporciona o estudo de imagens multiplanares com melhor delineação do alvo a ser tratado. Com a evolução das diversas técnicas neurocirúrgicas funcionais e dos tratamentos radioterápicos que atualmente permitem altas taxas de dose e a possibilidade de aplicação de radiação com melhor precisão no tecido alvo, a acurácia do alvo passa a ser fundamental, pois se reverte em efetividade do tratamento implementado.

Para combinar a acurácia espacial da TC com a alta definição da RM utiliza-se a fusão de imagens no planejamento cirúrgico. No entanto, basearse na fusão de imagens envolve também erros inerentes ao método, como por exemplo: a fusão de imagens que consiste em fundir uma imagem de TC com uma imagem de RM utilizando-se como referência pontos em comum nas duas imagens por meio de métodos manuais ou automatizados; qualquer erro na atribuição das referências ou na utilização de cortes de imagem diferentes na TC e RM resultará em erro geométrico no resultado da fusão. Além disso, registros baseados em referências externas, colocadas na pele, estão especialmente propensas a distorções (Fransson et al., 2001). Mesmo a localização baseada em referências ósseas, mais rígidas e menos passíveis de distorção, por conta de menor proximidade do isocentro em relação às referências de superfície, pode resultar em distorções significativas quando imagens de RM são adquiridas em magnetos que possuem gradientes de baixa homogeneidade e linearidade. Com a correção 
adequada da $\mathrm{RM}$, a precisão da fusão $\mathrm{RM} / \mathrm{TC}$ é mais fidedigna e o uso direto de imagens de RM poderia ser adotado como rotina (Fransson et al., 2001; Lee et al., 2003; Chen et al., 2004).

Atualmente, existe uma tendência para o uso de magnetos de alta potência com a finalidade de permitir o uso e associação de outras técnicas como os mapas de anisotropia fracionada, a tractografia e a espectroscopia. Em todos, o aumento no campo magnético melhora a sensibilidade e resolução dos tratos e do espectro produzido (Gruetter et al., 1998). Com o aumento do numero de procedimentos estereotácticos tanto para a intervenção neurocirúrgica funcional direta quanto para $\circ$ planejamento radioterapêutico, o uso de RM 3T acompanha esta mesma tendência (Wang et al., 2004a). Com relação à imagem anatômica, a Razão Sinal-Ruído (do inglês Signal to Noise Ratio - SNR) aumenta linearmente com a força do campo $B_{0}$ (Vaughan et al., 2001; Schmitz et al., 2005). Alternativamente, o SNR pode permanecer inalterado em troca de uma redução no tempo para aquisição das imagens, o que pode ser particularmente vantajoso para doentes em condições críticas na qual a imobilização prolongada é difícil. As distorções por desalinhamento do $B_{0}$, e efeitos no campo provocados pelos doentes, são proporcionais à força do $B_{0}$, e, portanto, a compreensão detalhada das distorções geométricas em campos magnéticos elevados torna-se ainda mais importante. Frequentemente sugere-se o uso do maior gradiente de leitura possível para que se possam reduzir os efeitos das distorções em $B_{0}$ (Bakker et al., 1992; Emami et al., 2003; Ten Haken et al., 1992; Fransson et al., 2001). Essa prática aumenta a largura de banda por 
pixel e reduz o tempo de leitura do sinal. Com isso, ocorre a diminuição do SNR e perde-se um dos benefícios primordiais do magneto de alto campo. Obviamente, existem vantagens e desvantagens na aquisição de imagem em campos de alta potência. Desde que se garanta que não haja distorções imagem significativas em 3T, e que possam ser detectadas e corrigidas, essas imagens podem ter papel fundamental em neurocirurgias estereotácticas e radioterapia.

Finalmente, é notório que distorções causadas por não linearidades nos gradientes são constantes para magnetos diferentes. Distorções por heterogeneidade do $B_{0}$ e efeitos de suscetibilidade variam entre os aparelhos de maneira inversamente proporcionais, importante à intensidade do gradiente de leitura (Bakker et al., 1992; Tanner et al., 2000). Apesar dos efeitos de suscetibilidade variarem em cada doente, as distorções de $B_{0}$ e de gradiente são específicas de cada aparelho. Baseando-se no fato de que os efeitos da anatomia são irrelevantes ou podem ser determinados independentemente (Bhagwandien et al., 1992; Jezzard e Balaban, 1995), seria possível predizer que existe distorção de imagens sem a necessidade de medidas detalhadas da distorção para cada imagem de cada doente. Isso proporcionaria uma economia de tempo considerável e aumentaria a aplicabilidade clínica da correção da distorção em imagens geradas pela RM.

Deste modo, o desenvolvimento de novas técnicas para redução de distorções pode proporcionar 0 melhor 0 delineamento de alvos estereotácticos mesmo em face de heterogeneidades de campo. 
2 Objetivos 
a) Comparar quantitativamente a precisão na mensuração de distâncias conhecidas de pontos determinados em imagens de ressonância magnética e tomografia computadorizada utilizando um modelo tridimensional com alvos (MTA), análogos aos alvos de estereotaxia utilizados durante procedimentos cirúrgicos que empregam esta tecnologia.

b) Determinar clinicamente a viabilidade de utilização da ressonância magnética em doentes como método de obtenção de imagens a serem utilizadas no planejamento de procedimentos estereotácticos encefálicos. 
3 REVISÃo dA LITERATURA 


\subsection{Princípios da Estereotaxia}

A localização e análise funcional das estruturas intracerebrais é objeto de interesse dos neurocientistas desde o advento da neurologia. Parte dos primeiros experimentos que tinham o intuito de correlacionar referências externas a estruturas cerebrais e suas funções no trabalho de Franz Joseph Gall (1758-1828) por meio de procedimentos de craniometria e defendia a doutrina da, frenologia, a qual associava irregularidades no crânio a características psicológicas do indivíduo (Lyons, 1987). Embora seu trabalho não apresentasse fundamentação científica e não fosse amplamente aceito, caracterizou um esboço na tentativa de correlacionar funções cerebrais com pontos de referência externos.

A investigação sobre a localização das funções cerebrais foi limitada por muitos anos aos estudos anatômicos e funcionais em animais além de correlações clínico-patológicas em humanos com doenças neurológicas. Com o nascimento da neurocirurgia no final do Século XIX, houve oportunidade para o estudo do cérebro e suas estruturas. Mesmo assim, estruturas cerebrais profundas continuavam relativamente inacessíveis aos procedimentos e experimentos guiados por visão direta. A neurocirurgia estereotáctica surgiu desde essa necessidade, isto é, de técnicas mais efetivas na identificação de estruturas subcorticais, que fossem reprodutíveis e menos invasivas, para que os danos ao córtex adjacente fossem mínimos. 
A palavra estereotaxia vem do grego e significa "arranjo ordenado em três dimensões", baseia-se no princípio que qualquer ponto no cérebro pode ser determinado a partir de um sistema de coordenadas específicas utilizando-se medidas precisas. O conceito de coordenadas cartesianas é baseado nos princípios desenvolvidos pelo grande filósofo e matemático francês René Descartes, do Século XVII (Descartes, 1966), e forma a base da maioria dos sistemas estereotácticos modernos. Descartes defendia o princípio que qualquer ponto no espaço pode ser definido pela sua relação com três planos: $x, y$ e $z$ que se interseccionam em ângulos retos (Figura 1).

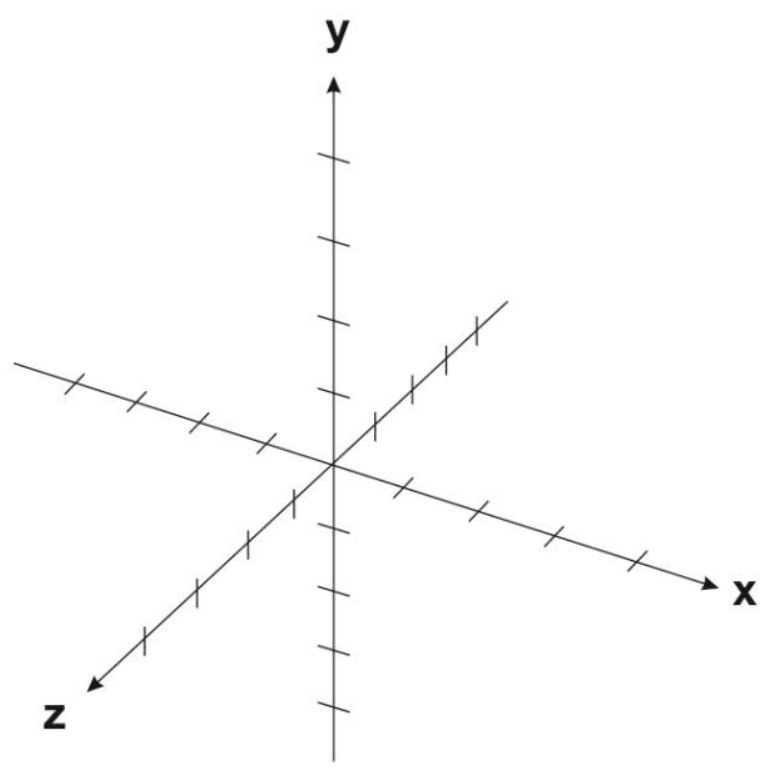

Figura 1 - Os três eixos cartesianos " $x$ ", " $y$ " e " $z$ " e a intersecção em $90^{\circ}$ entre eles

Os três eixos cartesianos " $x$ ", "y" e "z"; encontram-se em um ponto definido como a origem ou ponto "zero" (al-Rodhan e Kelly, 1992). Qualquer ponto no espaço pode ser definido pela distância a partir desses três planos de referência. Ao utilizar o sistema cartesiano em animais um plano sagital mediano é utilizado como referência, enquanto um plano basal perpendicular 
ao primeiro define o segundo plano. Historicamente, o plano basal passava através do meato auditivo externo e bordas inferiores das órbitas, o que é similar ao plano de Frankfurt, utilizado por antropólogos durante as mensurações de crânio em espécimes coletados. O uso prático da estereotaxia em primatas exigia a elevação desse plano em $10 \mathrm{~mm}$ para contemplar a base do cérebro. O terceiro plano também atravessava 0 meato auditivo externo de maneira ortogonal ao plano sagital médio e basal. O sistema de coordenadas cartesiano foi a base para o desenvolvimento dos sistemas avançados de estereotaxia (Gildenberg, 1990).

Outro sistema de estereotaxia relacionado ao sistema cartesiano, embora menos utilizado, é baseado no sistema de coordenadas polares ou esféricas. Ao contrário de três distâncias, os pontos-alvo são definidos por uma distância e dois ângulos $(R, \theta$, e $\omega)$ a partir de um ponto de referência. Esse método foi utilizado, anteriormente, acoplado ao sistema fixado à trepanação e, atualmente, é utilizado em conjunto com coordenadas cartesianas nos sistemas acoplados ao arco estereotáxico. Como esses sistemas necessitam de conhecimento de geometria esférica e tabelas trigonométricas, a maioria dos cirurgiões realizam os cálculos por meio de softwares apropriados (Gildenberg, 1990).

Existem outras maneiras pelas quais um ponto pode ser localizado no espaço. Por exemplo, as linhas representando os eixos de um sistema de coordenadas não necessitam ser perpendiculares umas as outras, embora as mesmas necessitem ser não paralelas e contenham em cada uma delas informação independente sobre cada ponto. Alternativamente, o ponto em 
um plano pode ser descrito especificando-se sua distância da origem, ou seja, seu raio (r) e ângulo (comumente chamado $\theta$ ) utilizando um sistema de coordenadas polares. O mesmo conceito pode ser estendido para três dimensões utilizando-se um sistema de coordenadas cilíndricas com especificação de distância adicional ao longo do eixo (Z) perpendicular ao plano original. Outra maneira para a utilização do sistema esférico de coordenadas onde é especificado um raio e dois ângulos $(\theta$ e $\omega$ perpendiculares entre si) descrevendo a direção a partir da origem.

Todos esses sistemas são matematicamente diversos porem equivalentes em termos de objetivo práticos em sua aplicação na estereotaxia, isto é, definir precisamente a localização de um ponto no espaço permitindo a interconversão das coordenadas entre eles. É elementar o exercício de transformação das coordenadas de um ponto $(r, \theta)$ de um sistema bidimensional polar em coordenadas $x, y$ em um sistema bidimensional cartesiano:

$$
\begin{aligned}
& x=r \cos \theta \\
& y=r \operatorname{sen} \theta
\end{aligned}
$$

Outra conversão semelhante a partir de coordenadas esféricas tridimensionais é representada pelas fórmulas:

$$
\begin{gathered}
x=r \operatorname{sen} \theta \cos \varphi \\
y=r \cos \theta \operatorname{sen} \varphi \\
z=r \cos \theta
\end{gathered}
$$


Uma variedade de métodos imagem bi ou tridimensionais podem ser empregadas em um procedimento estereotáctico. A informação espacial a partir de estudos de imagem, atlas, arcos estereotácticos e outros digitalizadores intraoperatórios precisam ser codificadas ou validadas dentro do espaços de coordenadas estereotácticas. Considerando primeiramente os estudos de imagem, as coordenadas de imagem tomográfica são facilmente definidas. A representação gráfica desse corte é gerada utilizando as coordenadas próprias do espaço estereotáctico. Por convenção, a coordenada $x$ é determinada ao longo do eixo direito-esquerdo da imagem e a coordenada y ao longo do eixo posterior-anterior. Entretanto, na era préTC, a coordenada $x$ referia-se a dimensão anterior posterior numa radiografia em perfil, a coordenada y ao longo da distância inferior-superior e a coordenada z na dimensão direita-esquerda. Com isso, em qualquer imagem de TC bidimensional (ou similar como RM, tomografia por emissão de prótons [PET] ou tomografia computadorizada por emissão de fóton único [SPECT]) pode-se especificar a localização de um pixel em relação às coordenadas $x$ e $y$ (Gildenberg, 1990).

O manejo do espaço tridimensional do volume intracraniano, em neurocirurgia funcional, é fundamental, e informações adicionais devem ser acrescentadas para esse cálculo espacial. A localização bidimensional do alvo em relação ao centro do espaço estereotáctico, assim como a topografia de outras estruturas importantes devem fazem parte da imagem seccional. As coordenadas podem ser determinadas de várias maneiras. Comumente, utiliza-se referenciais, também chamados de fiduciais em forma 
de "N" fixados ao halo estereotáctico na porção anterior e laterais (Anexo A). Deste modo calcula-se o centro do espaço estereotáctico na intersecção das diagonais desde os fiduciais nos vértices da imagem. A coordenada $\mathrm{X}$, a menor distancia entre o alvo e o eixo $\mathrm{Y}$, enquanto o mesmo se faz para encontrar a coordenada $\mathrm{Y}$ em relação ao eixo $\mathrm{X}$. A coordenada $Z$ é incorporada quando se adiciona, às coordenadas bidimensionais, a profundidade, ou seja, a menor distância do alvo no plano perpendicular ao plano do halo estereotáctico. Deste modo, o endereço tridimensional para qualquer ponto dentro do espaço estereotáctico pode ser determinado dentro do estudo imagenológico (Gildenberg, 1990).

Ainda segundo o autor, existem duas configurações possíveis dentro de um sistema ortogonal tridimensional. Dado os eixos $x$ e $y$ de uma imagem, o eixo positivo z estende-se a partir do arco estereotáctico. Dependendo do volume a ser estudado o eixo pode estender-se no sentido rostral ou caudal.

A incorporação de informações anatômicas derivadas de atlas relacionadas à esterotaxia é dependente de organização semelhante da informação em um espaço de coordenadas. Quase todos os atlas estereotácticos são cartesianos, e pela perspectiva matemática, diferem primariamente em termos de seleção da origem do sistema de coordenadas, orientação dos eixos, metodologia de mensuração e intervalos de obtenção de dados. Independentemente de características particulares, cada atlas tem um endereço tridimensional único (cortes anatômicos compilados em um volume tridimensional em maneira análoga ao conjunto de cortes de TC) para cada ponto anatômico de interesse, permitindo manipulação 
subsequente e incorporação desta informação no calculo estereotáctico. Portanto, o papel fundamental do halo estereotáctico é de definir um espaço de coordenadas referentes ao volume intracraniano a ser estudado. Deste modo, permite $\mathrm{o}$ corregistro das imagens com atlas anatômicos e eventualmente outros estudos de imagem do mesmo objeto que possam trazer diferentes informações a fim de se definir o alvo desejado.

Existem diversos tipos de sistemas estereotácticos disponíveis para uso clínico. Os sistemas de Leksell, Talairach, Hitchcock são alguns exemplos de arcos baseados no coordenadas cartesianas. No Brasil, temos o arco Teixeira-Matos (TM) da empresa Micromar ${ }^{\circledR}$ aprimorado de maneira pioneira pelo professor Manoel Jacobsen Teixeira a partir do sistema desenvolvido por Hitchcock (Hitchcock e Tsukamoto, 1974; Hitchcock, 1978). Esse último também é baseado no sistema cartesiano e é o sistema mais utilizado hoje na América Latina e parte da Europa Oriental. Sistemas isocêntricos, como o TM Micromar e Leksell, tendem a ser mais versáteis pois têm o atrativo e conveniência de permitir o ajuste livre dos ângulos do arco ou semiarco, apontando a extremidade da sonda diretamente ao alvo. Consequentemente a trajetória é determinada pelo alvo e dois ângulos, um ântero-posterior e outro latero-lateral, os quais determinam, ou são determinados pelo ponto de entrada de acordo com a necessidade.

No espaço de coordenadas do sistema estereotáctico Brown-RobertWells (BRW) os alvos e trajetórias são definidos por quatro ângulos associado a comprimento definido, constituindo exemplo de método não cartesiano (Brown, 1979). O seu desenvolvimento foi permitido pelo avanço 
da tecnologia computacional que permitiu conversões de coordenadas cartesianas para coordenadas esféricas de maneira prática e rápida.

Em resumo, o sistema estereotáctico permite a criação de um espaço que contempla coordenadas tridimensionais milimétricas que são corregistradas à imagem pela fixação do halo ao crânio e a presença dos fiduciais ao halo, durante a aquisição das imagens. A partir deste momento, as referencias são seguras e precisas, ou seja, pode-se localizar qualquer ponto desejado no espaço volumétrico pertinente demonstrado na imagem referência.

\subsection{RM com Magneto de Alta Potência}

A RM é um instrumento diagnóstico extremamente poderoso por permitir imagem de tecidos moles e com variadas concentrações de água em alta definição, tornando-se a modalidade ideal para delineação de alvos cerebrais (Barth et al., 2007).

O sinal da RM é derivado a partir dos átomos de hidrogênio não pareados, alinhados na mesma direção do campo magnético do aparelho de RM. O número de prótons alinhados, e, consequentemente, a intensidade do sinal de RM gerado é diretamente proporcional à força daquele campo magnético. Portanto, a base para o contínuo desenvolvimento de magnetos de alta potência é visar o aumento do sinal emitido pelos prótons (AlvarezLinera, 2008).

Inicialmente, os sistemas de RM contavam com menos de 0,6 Tesla (T) de magnitute do campo magnético. Em 1982, os sistemas de 1,5T foram introduzidos e logo ganharam espaço como a referência em RM de alta 
qualidade. Os primeiros sistemas de 3,0T foram disponibilizados em 1999, mas por razões práticas, incluindo projetos e protocolos inadequados de bobinas de radiofrequência $(\mathrm{RF})$, seu uso permaneceu limitado à pesquisa e imagem cerebral por muitos anos. Mesmos essas aplicações limitadas demonstraram superioridade na relação sinal-ruído (RSR) [signal to noise ratio], resolução espacial e temporal, relação contraste-ruído e resolução de espectro comparados com os mesmos parâmetros de 1,5T. Pesquisas mais recente focam a expansão de aplicações clínicas da RM de 3,0T em outras partes do corpo e com finalidades de auxílio em tratamento (Alvarez-Linera, 2008).

A transição do uso de equipamentos de baixo campo para aqueles de alto campo impõe dificuldades. Embora as lições aprendidas no uso de ressonância com campos magnéticos menos potentes tenham auxiliado muito os pesquisadores, o aumento do campo magnético introduziu problemas e imprecisões. Com o ganho na RSR, houve também um aumento da heterogeneidade do campo magnético. Pela RM de 3,0T possuir maior sinal de RF, isso resulta em maior interferência na transmissão e recepção de RF, o que pode produzir variações na intensidade do sinal ao longo da imagem. Além disso, a energia depositada é proporcional ao quadrado do campo magnético estático. Com isso, sequências de pulso de 3,0T são muito mais suscetíveis a limitações por agências reguladoras de saúde por apresentar maior deposição energética e taxa de absorção específica (SAR) tecidual. Entretanto, esses desafios são superáveis com as novas bobinas em desenvolvimento e sequências de pulso com parâmetros cuidadosamente escolhidos para cada tipo de imagem e região a ser estudada (Alvarez-Linera, 2008). 
Outros obstáculos técnicos incluem os tempos de relaxação tecidual alterados quando submetidos a campos magnéticos de alta intensidade. Os tempos de T1 dos tecidos a 3.0T podem necessitar de aumento no tempo de repetição (TR) e consequentemente, tempo de aquisição. Essa troca prejudica diretamente uma das vantagens da RM de 3T que seria o aumento da velocidade de aquisição de imagem. Adicionalmente, por conta da maior frequência da ressonância a $3 \mathrm{~T}$, os artefatos de deslocamento químico, conhecidos como chemical shift, são mais pronunciados. Finalmente, implantes metálicos que são seguros a 1,5T não são necessariamente seguros a 3.T (Alvarez-Linera, 2008).

\subsection{O Problema da Distorção}

A RM utiliza um campo magnético de intensidade constante, $B_{0}$, e três gradientes pulsáteis lineares de campo magnético (campos magnéticos que se modificam linearmente ao longo de uma distância) para localizar e criar imagem de pontos em um objeto. Esses diferentes gradientes são denominados gradientes de leitura ou codificado por frequência, codificação de fase e seleção de corte. As distorções geométricas ocorrem quando o $B_{0}$ e os campos de gradientes são perturbados por inúmeras razões (Baldwin et al., 2007).

Existem duas causas básicas potenciais de distorção geométrica em RM: não linearidade do gradiente e resonance offset. O último pode ainda ser dividido em duas categorias de acordo com sua origem: chemical shift e heterogeidade do campo magnético. A heterogeneidade do campo 
magnético pode ser induzida pelo próprio aparelho ou pelo objeto em questão. Na prática, a não linearidade e heterogeneidade do campo magnético, induzida pelo objeto, são as fontes de distorção mais importantes (Sumanaweera et al., 1994a e 1994b; Wang et al., 2004a, 2004b e 2004c).

\subsubsection{Não linearidade do campo magnético}

Os campos magnéticos dos aparelhos de RM são produzidos por correntes que passam através do conjunto de bobinas ortogonais e, embora essas bobinas resultem em gradientes lineares precisos, na prática algumas imperfeições existem. A distorção geométrica, das imagens relacionadas a tais imperfeições, é referida como distorção de não linearidade do gradiente. Pelo fato do eixo ortogonal, em que a bobina é manufaturada, ser alinhada com o eixo do magneto principal, a acurácia geométrica é geralmente maior ao longo do eixo do magneto (Sumanaweera et al., 1993; Sumanaweera et al., 1994a e 1994b).

\subsubsection{RM bi e tridimensional}

A RM pode ser dividida em duas categorias: bidimensional (2D) e tridimensional (3D). $\mathrm{Na} \quad \mathrm{RM} \quad 2 \mathrm{D}$, vários cortes são adquiridos sequencialmente para construir uma imagem em volume 3D. Na RM 3D, o volume 3D é excitado simultaneamente e a imagem 3D é adquirida em um conjunto sequencial de cortes 2D. A distorção ocorre de acordo com o método de aquisição de imagem (Sumanaweera et al., 1994a e 1994b). 


\subsubsection{D RM}

Com a RM 2D, a não linearidade do gradiente manifesta-se de três maneiras. A primeira é a distorção em barril que pode atingir $4 \mathrm{~mm}$ no campo de visibilização (field of view - FOV) de $200 \times 200 \mathrm{~mm}^{2}$ situado no isocentro do gradiente. O segundo, o efeito de distorção da fatia (potato chip) que pode levar a distorção de até $4 \mathrm{~mm}$ para cortes de $100 \mathrm{~mm}$ fora do isocentro das bobinas do gradiente. Essa região de interesse corresponde ao típico FOV numa aquisição de crânio. Finalmente, o efeito gravata borboleta (bow tie) que também pode ocorrer como resultado de não linearidade do gradiente (Sumanaweera et al., 1994a e 1994b).

Muitos fabricantes de RM utilizam modelos matemáticos para corrigir a distorção em barril. Entretanto, até o momento, nenhum algoritmo corrigiu satisfatoriamente o efeito potato chip na RM 2D. O problema tem origem no fato de que os cortes não são completamente contínuos na RM 2D. Isso é provocado pelo efeito de saturação da radiofrequência dos cortes adjacentes. A espessura do corte geralmente é muito grande para permitir resolução adequada da distorção. Com informações de cortes perdidas, qualquer tipo de correção baseada em um novo escaneamento ou interpolação não será precisa o suficiente. Para atenuar esse problema, pode-se utilizar aquisição 3D em vez de 2D (Sumanaweera et al., 1994a e 1994b). 


\subsubsection{Ressonância de Aquisição Tridimensional (RM 3D)}

$\mathrm{Na}$ RM 3D, como todo o campo de imagem é excitado ao mesmo tempo e o gradiente para seleção do corte não é tão intenso, os efeitos de potato chip e bow tie não são tão importantes. O único tipo de distorção geométrica produzida pela não linearidade é a distorção em barril, que está presente nos três eixos. Embora essa distorção possa atingir até $4 \mathrm{~mm}$ num FOV de $200 \times 200 \times 200 \mathrm{~mm}^{3}$ (situado no isocentro do gradiente), ela pode ser corrigida com precisão de $1 \mathrm{~mm}$ utilizando as distorções previstas em campos magnéticos gerados por essas bobinas. Embora todos os fabricantes tenham incorporado alguma forma de correção para 2D no seu programa, a correção completa em 3D pode não estar disponível ao usuário (Sumanaweera et al., 1993; Sumanaweera et al., 1994a e 1994b).

\subsection{Resonance Offset}

A RM utiliza sinais nucleares magnéticos de ressonância que dependem da razão giromagnética (uma propriedade magnética do átomo) do material do objeto e do campo $B_{0}$. Como a localização da imagem em RM depende do estabelecimento de relação linear entre espaço e frequência de ressonância, qualquer mudança na frequência causada por mecanismos outros que os gradientes de imagem lineares levam a distorções geométricas da imagem. Esses deslocamentos têm origem em desalinhamentos da ressonância, que são mudanças indesejáveis nas frequências dos sinais nucleares magnéticos de ressonância, que podem ser causados por mudanças tanto na razão giromagnética como campo $B_{0}$ 
(Sumanaweera et al., 1994a e 1994b, Wang et al., 2004a, 2004b e 2004c; Viard et al., 2008; Cheng et al., 2009).

As distorções geométricas causadas por alterações na razão giromagnética e campo $B_{0}$ são chamadas de chemical shift e distorções por heterogeneidade do campo magnético, respectivamente. É importante frisar que distorções que resultam de resonance offsets são manifestadas apenas na direção do gradiente de leitura (frequency enconding) da imagem Sumanaweera et al., 1994a e 1994b).

\subsubsection{Deslocamento Químico (Chemical Shifts)}

A razão giromagnética dos átomos de hidrogênio em um objeto pode variar entre diferentes moléculas que contém hidrogênio. Essa variação pode causar deslocamentos de um objeto dentro de uma imagem, muitas vezes provocando a aparição de dois objetos num mesmo pixel. Com isso, os deslocamentos químicos não podem ser corrigidos após a aquisição da imagem. Em imagens de alto campo magnético, áreas de gordura na imagem deslocam-se aproximadamente 1,7 pixels ao longo do gradiente de leitura (com $B_{0}$ de $1,5 \mathrm{~T}$ e uma largura de banda de leitura de $\pm 16 \mathrm{~Hz}$ ) em relação as áreas compartimentais de água. Isso corresponde a aproximadamente $1,5 \mathrm{~mm}$ em protocolo de escaneamento neurocirúrgico de rotina. Como o deslocamento químico pode ser suprimido por saturação seletiva ou métodos de excitação seletivos, isso não é um problema importante na localização estereotáctica quando a gordura não é necessária na imagem (Rosen et al., 1984; Spielman et al., 1991). Além disso, a 
imagem da gordura e dos tecidos mais hidratados podem ser adquiridos separadamente e logo após sobrepostos, criando imagens livres de deslocamentos químicos (Dixon, 1984).

\subsubsection{Heterogeneidade do Campo Magnético}

Heterogeneidades do campo magnético são produzidas pelos aparelhos de RM e o objeto alvo da aquisição de imagem (Sumanaweera et al., 1994a e 1994b). Esses dois tipos de distorção serão apresentados em detalhe a seguir.

\subsubsection{Distorção induzida pelo aparelho de ressonância magnética}

O principal campo magnético do aparelho de RM é projetado para ser altamente constante dentro do FOV. Entretanto, existem imperfeições residuais que podem provocar interferências no campo magnético (que seria supostamente constante). Por meio de um processo chamado "shimming", o $B_{0}$ pode aproximar-se da constância pela da aplicação de correntes apropriadas para alinhamento das bobinas (Chang e Fitzpatrick, 1992). Com a melhora progressiva dos magnetos e métodos de alinhamento, a heterogeneidade induzida pelo aparelho não é mais um problema significante para localização estereotáctica acurada utilizando a RM. Além disso, qualquer variação residual sistemática em $B_{0}$ pode ser compensada utilizando métodos de correção de distorção já descritos na literatura (Chang e Fitzpatrick, 1992; Sumanaweera et al., 1993). 


\subsubsection{Distorção induzida pelo objeto}

A forma mais complexa de distorção geométrica encontrada em RM resulta da heterogeneidade do campo magnético principal induzido pelo próprio objeto estudado. Tal distorção é especialmente complexa, pois depende tanto do material presente no objeto quanto sua forma e estrutura. Como no deslocamento químico, este ocorre apenas ao longo da direção do gradiente de leitura (Chang e Fitzpatrick, 1992).

Quando um objeto contendo dipolos magnéticos, como átomos de hidrogênio, é colocado em um campo magnético constante produzido por um aparelho, o campo é perturbado pela magnetização induzida. O grau em que essa perturbação ocorre é medida em termos da suscetibilidade magnética, chi, do material. O efeito dessa variação no campo magnético ocorre pelo menos em três diferentes modos (Ludeke et al., 1985; Sumanaweera et al., 1994a e 1994b):

a) Em RM 2D os cortes podem não serem planos, ou seja, não lineares ao longo do objeto examinado.

b) $\mathrm{Na} \mathrm{RM} 2 \mathrm{D}$ e 3D, partes das estruturas do objeto podem ser deslocadas entre elas ao longo da direção de leitura. Entretanto, a distorção geométrica não ocorre ao longo da direção da codificação de fase (Ludeke et al., 1985; Sumanaweera et al., 1994a e 1994b).

c) $\mathrm{Na} \mathrm{RM} 2 \mathrm{D}$ e 3D, a imagem pode mostrar falsas variações na intensidade concomitantes como os efeitos de mudança na forma (p.ex: efeito barril) descritos anteriormente.

A heterogeneidade do campo magnético induzida pelo objeto ocorre 
nas sequências eco e spin-eco, especialmente se o gradiente de leitura é pequeno e o campo $B_{0}$ é de alta potência (Ludeke et al., 1985; Rosenthal et al., 1990). No tecido, os sinais de RM são gerados por prótons. Gordura e água são dois tipos básicos de moléculas em que os prótons dão origem aos sinais de RM. Todos tecidos moles contêm uma grande fração de água e, com isso, a suscetibilidade magnética do tecido pode ser aproximada com a da água. O mesmo ocorre com o tecido ósseo esponjoso. Em contraste, o osso cortical e o ar não geram sinais significativos na RM. Entretanto, ambos podem distorcer os campos magnéticos nos tecidos próximos que geram os sinais de RM resultando em distorção geométrica próxima a estas interfaces.

A suscetibilidade magnética da água em relação a do ar é -9,05ppm, enquanto a do osso cortical é $-8,86$ ppm. Utilizando esses valores, a distorção geométrica próxima da interface ar/osso e ar/tecido pode ser estimada na ordem de $2,1 \mathrm{~mm}$, quando, por exemplo, $B_{0}$ é $1,5 \mathrm{~T}$ e a largura de banda é $\pm 16 \mathrm{kHz}$. Em contraste, a distorção nas interfaces osso/tecido é estimada em apenas 0,05 mm (Sumanaweera et al., 1994a e 1994b).

Embora a distorção por heterogeneidade de campo magnética e a induzida por objeto tenha sido quantificada em MTA de geometria conhecida, os testes em humanos com fins terapêuticos são raros. Entretanto, a precisão geométrica da RM pode se medida utilizando a TC como parâmetro (Schad et al., 1987) ou utilizando a direção do gradiente de fase (que não apresenta distorção) como um parâmetro interno (Sumanaweera et al., 1994a e 1994b). 


\section{MÉTodos}




\subsection{Modelo Tridimensional com Alvos para Estudo da Distorção e Halo Estereotáctico}

Foram adquiridas uma série de imagens do MTA em TC e RM. A TC foi utilizada como referência para o cálculo da acurácia geométrica da RM. Foram selecionados quatro pontos que eram claramente visíveis nas imagens de TC e RM. As imagens foram analisadas com o software MSA $3.50^{1}$ (Anexo B).

$\mathrm{OMTA}^{2}$ foi manufaturado a partir de um cilindro de acrílico com uma plataforma feita de policloreto de vinila (PVC) com as dimensões e características do halo estereotáctico de uso clínico. O sistema Micromar ${ }^{\circledR}$ (Diadema, São Paulo, Brasil) compatível com ressonância é baseado no sistema cartesiano de coordenadas e é constituído de fibra de vidro associada a epóxi o que permite alta resistência à movimentação mecânica e distorção não detectável na RM (Anexo A).

O modelo tridimensional com alvos foi preenchido com solução de ácido bórico a 3\% (água boricada) a fim de aumentar o sinal na RM e com isso promover melhor visibilização de sua imagem. Os marcadores referenciais (fiduciais) consistem de um sistema em forma de "N" que podem ser acoplados à, ou removidos da plataforma do MTA para aquisição da imagens. Dois tipos de fiduciais foram utilizados, um para a TC e o outro

Micromar Software Assistant - Micromar ${ }^{\circledR}$, Diadema, Brasil/ F 1719-96 [revisado em 2002]

2 Micromar $^{\circledR}$, Diadema, SP, Brasil. Este aparelho está de acordo com as normas internacionais de construção de arcos estereotácticos para uso médico em humanos [F 1266-89 revisado em 2002], registrado pela ANVISA. 
para a RM. Os fiduciais de RM são cilíndricos e feitos de tubos de acrílico e silicone de maneira que possam ser preenchidos com a solução de ácido bórico. A dimensão dos fiduciais laterais é de $140 \mathrm{~mm}$ e a do fiducial frontal é de $110 \mathrm{~mm}$. Os fiduciais da TC foram confeccionados a partir de Celeron com dimensões $140 \times 140 \times 140$ mm. Para aquisição das imagens o MTA foi posicionado exatamente como o paciente dentro da bobina de RM.

As imagens de TC foram obtidas no aparelho High Speed ${ }^{\circledR 3}$. Foram utilizadas cortes axiais de $2 \mathrm{~mm}$ sem intervalos com matriz de $512 \times 512$, pixel de 0,65 mm x 0,65 mm. As imagens de RM foram adquiridas no modo Spin Echo em T1, transverso, a 3T no aparelho Sigma $L X^{\circledR 4}$ e obtidas na bobina de oito quadrantes para crânio. $O$ tempo de repetição foi de 600 msec e o tempo echo (TE) foi de $15 \mathrm{~ms}$; o FOV utilizado foi de $380 \mathrm{~mm}$; com pixel de $256 \times 256 \mathrm{~mm}$; a espessura do corte foi de $4 \mathrm{~mm}$ com $1 \mathrm{~mm}$ de intervalo. Para cada aquisição duas imagens foram obtidas conforme o método descrito por Chang e Fitzpatrick (1992). A primeira imagem (normal i1) consiste de gradiente de leitura Gx orientado horizontalmente e o gradiente de fase orientado verticalmente. A segunda imagem (reversa - i2) foi obtida com o gradiente de leitura invertido em $180^{\circ}$, como uma imagem em espelho (Figura 2). Foram selecionados quatro pontos de referencia facilmente identificados na TC, nRM e rRM com as coordenadas $x, y$ e $z$. Cada ponto foi marcado três vezes para estimativa de erro sistemático. Foi utilizada a fórmula $\left(x_{n}+x_{r}\right) / 2=x_{c}$ onde $x_{n}$ (ponto da $\left.n R M\right), x_{r}$ (ponto da rRM) e $x_{c}$ (ponto corrigido). $O$ protocolo não envolveu a correção dos pontos $y$ e $z$ 
já que os mesmos apresentam distorção desprezível com já demonstrado em modelo matemático prévio (Chang e Fitzpatrick, 1992). As Figura 2 e 3 ilustram a modificação da sequência de aquisição.

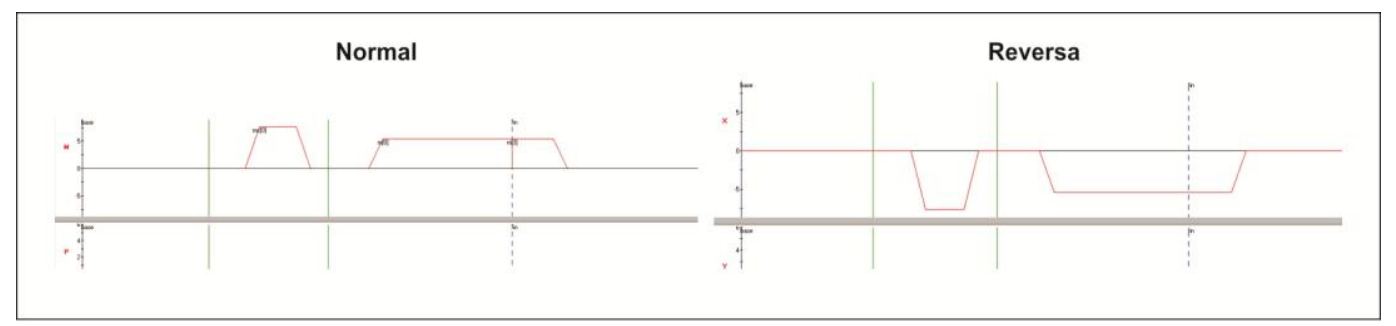

Figura 2 - Gráfico da sequência de RM normal e reversa. Note a inversão da primeira linha que se refere ao gradiente de leitura.

\subsection{Modelo Matemático para Cálculo e Correção da Distorção}

O sinal da RM advém de interações entre o estado magnético de determinados núcleos em um objeto e o campo magnético gerado pelo aparelho. Devido ao seu intenso sinal e abundância nos organismos, os prótons dos átomos de hidrogênio são os núcleos de interesse predominante na maioria das obtenções de imagem. Os prótons são excitados por um campo de radiofrequência oscilando em uma frequência ajustada a fim de parear a dos prótons imersos em campo magnético estático de uma magnitude específica "B". Na técnica de obtenção de imagem mais comum, seleção de cortes, um gradiente linear Gz na direção z é aplicado em campo estático de maneira que apenas os prótons no plano perpendicular ao eixo $z$ entrem em ressonância com o slice selection gradient $(\mathrm{Gz})$. Outros gradientes são aplicados em diferentes direções, phase-encoding (Gy) e read-out ou frequency-enconding (Gx), de maneira a obtermos uma imagem reconstruída tridimensionalmente a partir do sinal emitido pelos prótons em questão. 
Entretanto, existem basicamente duas potenciais causas de distorção geométrica na RM: não-linearidade do gradiente de campo e deslocamentos da ressonância. Esse último pode ainda ser subdividido em deslocamentos químicos e não-homogeneidades do campo magnético. Com isso, considera-se Be $(x, y, z)$ o desvio do campo $B$, ou seja, a distorção. Para expressar a distorção causada por $B_{e}$, serão consideradas $x 1, y 1, z 1$ como as coordenadas incorretas obtidas pelo aparelho $\mathrm{e} x, \mathrm{y}, \mathrm{z}$ como as coordenadas corretas dos prótons. Temos:

$$
z_{1}=z+\frac{B_{e}(x, y, z)}{G_{z}}
$$

As derivações dessas equações estão disponíveis em outra publicação derivada desta tese (Tavares et al., 2014). Cada um desses prótons excitados produzem sinal sinusoidal com mesma fase. Essas fases são deliberadamente dispersadas pela aplicação de gradiente Gy na direção y por tempo definido. Essa dispersão na presença de gradiente linear efetivamente codifica a coordenada y de cada próton em sua fase. Finalmente, um sinal é obtido durante a aplicação do terceiro gradiente Gx na direção x. Esse sinal é a soma dos sinais dos prótons cujas frequências são, por causa de Gx, uma função linear de x. Repetindo o processo de seleção da fatia com Gz, phase coding com Gy, e frequency-enconding na presença de Gx, temos no final a reconstrução do objeto a partir de múltiplas fatias obtidas. Utilizando a transformada de Fourier bidimensional desses sinais, obtemos uma distribuição dos sinais em $x$ e y que representam a distribuição do campo magnético $(\mathrm{M})$ dos prótons. Temos ainda que como 
resultante de $\mathrm{Be}$, não há distorção na coordenada y e, considerando a dimensão do gradiente magnético, a distorção na coordenada z é ínfima. Com isso, o principal foco de distorção ocorre na coordenada $\mathrm{x}$.

$$
x_{1}=x+\frac{B_{e}(x, y, z)}{G_{x}}
$$

Adicionalmente à distorção na posição, há também distorção na intensidade da imagem. Se for considerada $i(x, y, z)$ a imagem não distorcida e i1 $(x 1, y 1, z 1)$, a imagem distorcida, temos:

$$
i_{1}\left(x_{1}, y, z\right)=i(x, y, z) / J_{1}\left(x_{1}, y, z\right),
$$

onde $\mathrm{J} 1(\mathrm{x} 1, \mathrm{y} 1, \mathrm{z} 1)$ é o cálculo Jacobiano da transformação de $\mathrm{x}, \mathrm{y}, \mathrm{z}$ em $\mathrm{x} 1, \mathrm{y} 1, \mathrm{z} 1$ e considerado que $\mathrm{y} 1=\mathrm{y}$ pode-se demonstrar que:

$$
J_{1}\left(x_{1}, y, z\right)=1+\frac{1}{G_{x}} \frac{B_{e}(x, y, z)}{x}+\frac{1}{G_{z}} \frac{B_{e}(x, y, z)}{z} .
$$

É possível também corrigir os erros em $\mathrm{x}, \mathrm{z}$, e as intensidades de imagem descritas nessas equações. Referimo-nos a esse processo como "Retificação". Abaixo será descrita a técnica de retificação dos pontos. Como já descrito, uma simplificação considerável das equações pode ser obtida devido a grande dimensão de Gz. Por exemplo, em nossos experimentos o Gz será aproximadamente $6,0 \mathrm{mT} / \mathrm{m}$ enquanto $\mathrm{Gx}$ será de $0,98 \mathrm{mT} / \mathrm{m}$. Com isso, temos que $z 1=z$. Resulta que:

$$
i_{1}\left(x_{1}, y, z\right)=i(x, y, z) / J_{1}(x, y, z)
$$




$$
J_{1}\left(x_{1}, y, z\right)=1+\frac{1}{G_{x}} \frac{B_{e}(x, y, z)}{x} .
$$

Para a técnica de retificação, obtém-se uma imagem adicional (i2), utilizando os mesmos parâmetros, mas com reversão do gradiente em Gx conforme já descrito. Para i2 temos:

$$
\begin{gathered}
x_{2}=x \quad \frac{B_{e}(x, y, z)}{G_{x}} \\
i_{2}(x, y, z)=i(x, y, z) / J_{2}\left(x_{2}, y, z\right), \\
J_{2}\left(x_{2}, y, z\right)=1 \frac{1}{G_{x}} \frac{B_{e}(x, y, z)}{x} .
\end{gathered}
$$

Combinando as equações 2 e 7 obtém-se:

$$
X=\left(X_{1}+x_{2}\right) / 2
$$

Baseado nesse algoritmo, obtemos a retificação dos pontos com distorção geométrica corrigida.

Para poder assegurar a consistência interna dos dados e possível divergência entre os observadores, os Testes de Cronbach e Friedman foram aplicados, respectivamente (Perrin, 1995). Onze observadores voluntários da Divisão de Neurocirurgia Hospital das Clínicas da Faculdade de Medicina da Universidade de São Paulo (HC-FMUSP) foram selecionados para realizar as medidas a partir de três pontos no MTA (B, C e D) que eram claramente identificáveis na TC e RM (Figura 34). A partir 
dessas medidas, as coordenadas $x, y$ e $z$ foram obtidas. A análise das imagens foi feita utilizando-se o software MSA $3.50^{5}$ ) e o iSite PACS ${ }^{6}$.

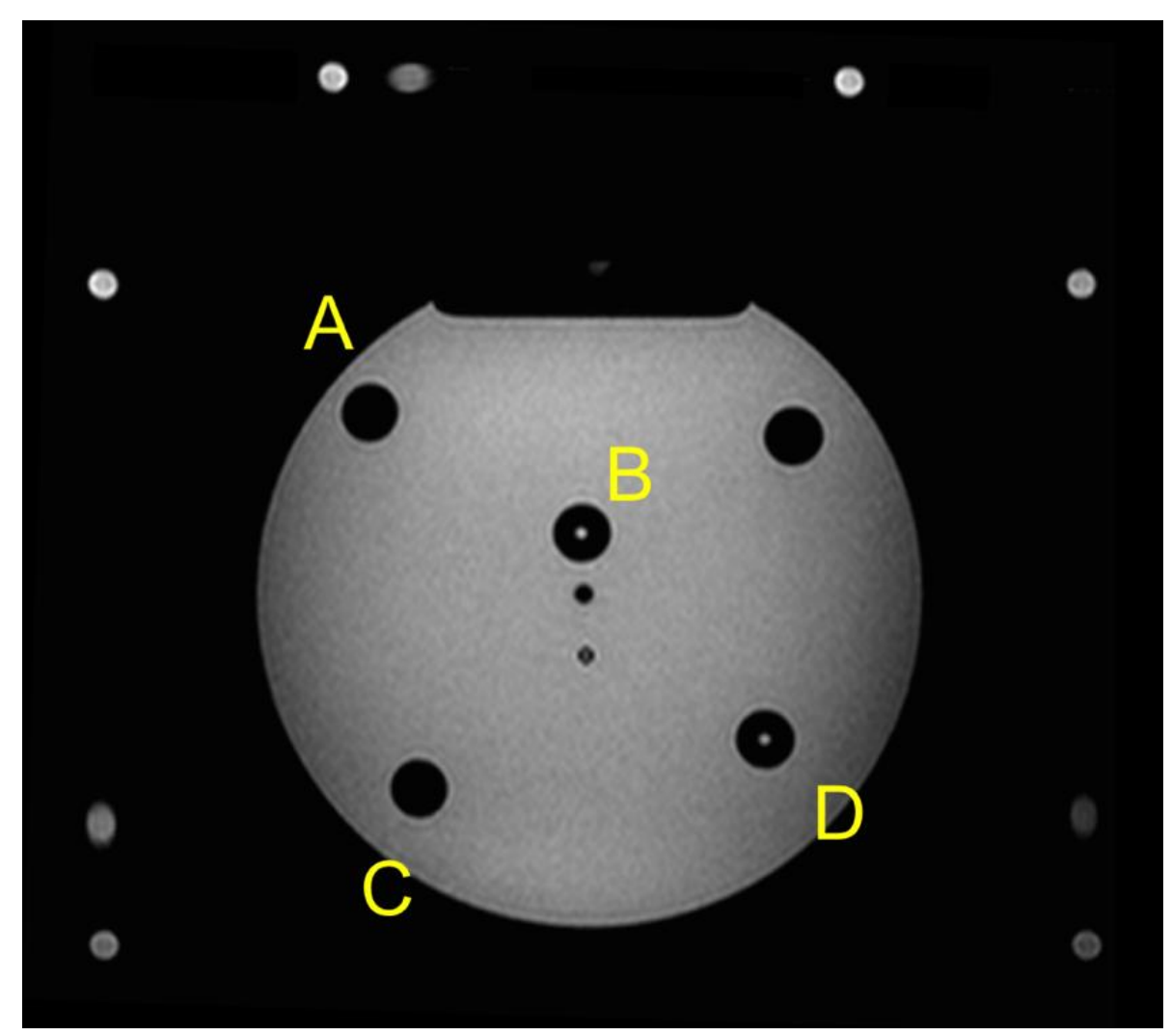

Figura 3 - Corte axial do MTA com os pontos A, B, C e D identificáveis

Para a análise da distorção e correção nos doentes, foi utilizado o teste dos postos sinalizados de Wilcoxon, com a finalidade de confirmar se houveram possíveis diferenças entre os dados da TC e os dados corrigidos. Além disso, foi complementada a análise com o cálculo do "poder do estudo" a partir do programa PS-Power And Sample Size Calculation (versão 3.0.43). A obtenção dos dados foi feita a partir da determinação de oito pontos que fossem claramente identificáveis na TC, RM e ressonância com

5 Micromar Software Assistant - Micromar.

6 Picture Archiving and Computerized System. Philips Medical Systems, Eindhoven, Netherlands. 
gradiente invertido (rRM) para cada doente. Os pontos selecionados não eram os mesmos entre os doentes devido às dificuldades técnicas de identificação dos mesmos pontos de TC, RM e rRM entre todos os doentes (Tabela 5).

\subsection{Seleção de Doentes}

O presente trabalho foi aprovado pelo Comitê de Ética em Pesquisa do Hospital das Clínicas da Faculdade de Medicina da Universidade de São Paulo e segue os regulamentos éticos internacionais a respeito dos procedimentos experimentais com seres humanos (Protocolo 1127/06 sessão 06.08.08) (Anexo C).

Foram selecionados prospectivamente e sequencialmente 20 doentes, após serem devidamente esclarecidos sobre os procedimentos e assinarem o Termo de Consentimento Livre e Esclarecido (Anexo D). Os doentes preencheram os seguintes critérios:

\subsubsection{Critérios de inclusão}

Doentes atendidos regularmente no HC-FMUSP, candidatos a procedimentos estereotácticos funcionais ou biópsias de lesões encefálicas guiadas pelo método estereotáctico que normalmente são realizados por TC. 


\subsubsection{Critérios de exclusão}

Doentes com qualquer contraindicação para realização de RM, incluindo doentes claustrofóbicos; com peso superior a 130 kg; portadores de marca-passos cardíacos, neuroestimuladores, clipes de aneurisma, próteses metálicas ou qualquer outro objeto metálico incompatível com a RM.

\subsubsection{Procedimentos de aquisição de imagens de CT e RM dos pacientes incluídos no estudo}

Conforme rotina do serviço de neurocirurgia funcional do HC-FMUSP, os doentes recebem a fixação do halo estereotáctico e são encaminhados para a aquisição de imagens de CT com o halo estereotáctico e fiduciais devidamente posicionados. Os doentes incluídos no estudo passaram pelo mesmo procedimento e adicionalmente tiveram também as imagens de RM obtidas permitindo que as imagens estereotácticas tanto de RM quanto as de CT do mesmo doente pudessem ser utilizadas neste estudo. É importante ressaltar que os procedimentos diagnósticos ou terapêuticos necessários à evolução clínicos foram baseados nos procedimentos rotineiros sem a interferência das imagens e dados obtidos para o estudo, ou seja, o fato do pacientes ter participado do estudo não interferiu em sei tratamento.

A impossibilidade de achar pontos comuns confiáveis na TC e RM também foi utilizada para excluir doentes da amostra (apenas um doente foi excluído após a análise do total de 20). 


\subsection{Análise Estatística}

Foi adotado o nível de significância de 5\% (0,050), para a aplicação dos testes estatísticos, ou seja, quando o valor da significância calculada (p) for menor do que $5 \%(0,050)$, observa-se uma diferença ou uma relação dita "estatisticamente significante"; e quando o valor da significância calculada (p) for igual ou maior do que $5 \%(0,050)$, observamos uma diferença ou relação dita "estatisticamente não-significante".

A partir dos 20 doentes e das respectivas imagens de TC e RM, foram considerados 152 pontos amostrais dentre as imagens para análise estatística. Conforme demonstra o Gráfico 1, a amostra foi calculada para que obtivéssemos poder de estudo > 0,999.

Usamos o programa SPSS (Statistical Package for Social Sciences), em sua versão 17.0, para a obtenção dos resultados. 
Gráfico 1 - Gráfico do poder do estudo em relação ao tamanho da amostra (Usando programa PS-Power and Sample Size Calculation, em sua versão 3.0 .43 , e considerando 152 pontos amostrais (pares de pontos formados pelas variáveis TC e CORREÇÃO), e com os valores de 0,23 para a diferença entre os desvios-padrão e 0,65 para a diferença entre as medianas, encontramos que o poder do estudo é > 0,999 , quando a significância adotada (' $p$ ' - erro do tipo I) vale $0,050(5 \%)$

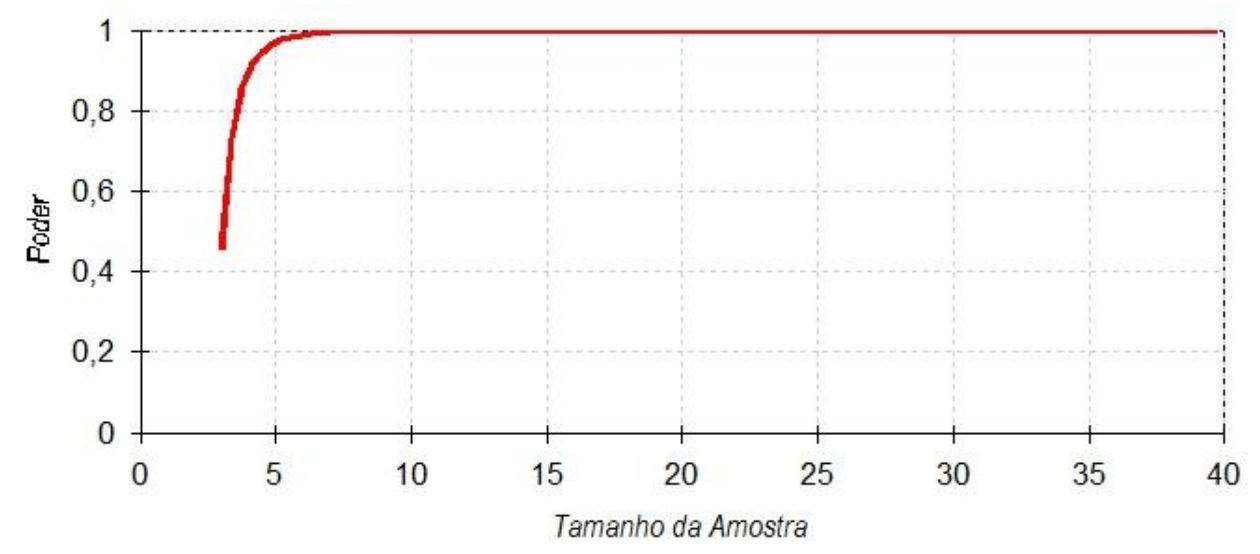




\section{Resultados}




\subsection{Análise da Distorção e Correção no MTA}

O estudo estatístico foi realizado apenas utilizando os dados do eixo X. Para determinar a consistência interna dos dados o teste de Cronbach, ou coeficiente de consistência, foi aplicado (Tabela 1).

Tabela 1 - Coeficiente de Cronbach para consistência dos dados

\begin{tabular}{lcc}
\multicolumn{1}{c}{ Imagem } & $\begin{array}{c}\text { Coeficiente } \alpha \text { de } \\
\text { Cronbach }\end{array}$ & $p$ \\
\hline Tomografia computadorizada & $>0,999$ & $<0,001$ \\
Imagem de ressonância magnética normal & $>0,999$ & $<0,001$ \\
Imagem de ressonância magnética reversa & $>0,999$ & $<0,001$ \\
\hline
\end{tabular}

As Tabelas 2 e 3 demonstram os dados obtidos no eixo $\times$ para as imagens de TC e RM.

Tabela 2 - Valores médios para os três pontos marcados por cada voluntário (pontos iguais para todos os voluntários) utilizando tomografia computadorizada

\begin{tabular}{|c|c|c|c|}
\hline Voluntários & $\mathrm{n}$ & Média dos 3 pontos da TC & $p$ \\
\hline $1 \mathrm{TC} x$ & 3 & 24,33 & \multirow{11}{*}{0,44} \\
\hline $2 \mathrm{TC} x$ & 3 & 24,33 & \\
\hline 3 TC $x$ & 3 & 24,33 & \\
\hline $4 \mathrm{TC} x$ & 3 & 24,67 & \\
\hline $5 \mathrm{TC} x$ & 3 & 24,67 & \\
\hline 6 TC $x$ & 3 & 24,67 & \\
\hline $7 \mathrm{TC} x$ & 3 & 24,67 & \\
\hline $8 \mathrm{TC} x$ & 3 & 24,33 & \\
\hline 9 TC $x$ & 3 & 24,33 & \\
\hline $10 \mathrm{TC} x$ & 3 & 24,33 & \\
\hline $11 \mathrm{TC} x$ & 3 & 24,67 & \\
\hline
\end{tabular}


Tabela 3 - Valores médios para os três pontos da RM após a correção da imagem

\begin{tabular}{|cccc|}
\hline Voluntários & $\mathbf{n}$ & Média dos 3 pontos da RM & $\mathbf{p}$ \\
\hline $1 \mathrm{MR} x$ & 3 & 25,20 & \\
\hline $2 \mathrm{MR} x$ & 3 & 25,23 & \\
\hline $3 \mathrm{MR} x$ & 3 & 25,37 & \\
\hline $4 \mathrm{MR} x$ & 3 & 25,22 & 0,152 \\
\hline $5 \mathrm{MR} x$ & 3 & 25,20 & \\
$6 \mathrm{MR} x$ & 3 & 25,20 & \\
\hline $7 \mathrm{MR} x$ & 3 & 25,20 & \\
\hline $8 \mathrm{MR} x$ & 3 & 25,23 & \\
\hline $9 \mathrm{MR} x$ & 3 & 25,22 & \\
\hline $10 \mathrm{MR} x$ & 3 & 25,22 & \\
\hline $11 \mathrm{MR} x$ & 3 & 25,20 \\
\hline
\end{tabular}

A Tabela 4 mostra os dados completos obtidos dos voluntários. Para todos os dados obtidos, o valor de $p$ encontrado foi maior que 0,05 ; indicando que as diferenças entre os observadores não foram estatisticamente significantes. Além disso, o processo de retificação provouse efetivo. A distorção media, após a correção, foi 1,05 mm (o espectro da distorção após a correção foi de 1,05 a 2,75 mm). A distorção antes da correção variou entre $0,7 \mathrm{~mm}$ e 3,7 mm dependendo da localização do alvo. A distância do alvo a partir do centro do sistema de coordenadas cartesianas determinou o nível das distorções, como prevê a teoria (Gráfico 2). A menor distorção foi encontrada no ponto B (próximo ao centro), enquanto a maior distorção foi evidente no ponto C (periferia da imagem). 
Tabela 4 - Dados totais obtidos da coordenada $x$ para cada tipo de aquisição de imagem, ponto escolhido e voluntário

\begin{tabular}{|ccccccccccccc}
\hline Voluntários & $\mathbf{1}$ & $\mathbf{2}$ & $\mathbf{3}$ & $\mathbf{4}$ & $\mathbf{5}$ & $\mathbf{6}$ & $\mathbf{7}$ & $\mathbf{8}$ & $\mathbf{9}$ & $\mathbf{1 0}$ & 11 \\
\hline TC (x) & & & & & & & & & & & \\
B & 0,1 & 0,1 & 0,1 & 0,1 & 0,1 & 0,1 & 0,1 & 0,1 & 0,1 & 0,1 & 0,1 \\
C & 36,3 & 36,3 & 36,3 & 36,3 & 36,3 & 36,3 & 36,3 & 36,3 & 36,3 & 36,3 & 36,3 \\
D & 36,5 & 36,5 & 36,5 & 37,5 & 37,5 & 37,5 & 37,5 & 36,5 & 36,5 & 36,5 & 37,5 \\
\hline MR (x) & & & & & & & & & & & \\
B & 1,5 & 1,5 & 1,5 & 1,5 & 1,5 & 1,5 & 1,5 & 1,5 & 1,5 & 1,5 & 1,5 \\
C & 34,1 & 34,1 & 35 & 34,1 & 34,1 & 34,1 & 34,1 & 34,1 & 34,1 & 34,1 & 34,1 \\
D & 40,2 & 40,2 & 40,2 & 40,2 & 40,2 & 40,2 & 40,2 & 40,2 & 40,2 & 40,2 & 40,2 \\
\hline rMR (x) & & & & & & & & & & & \\
\hline B & 0,8 & 0,9 & 0,8 & 0,8 & 0,8 & 0,8 & 0,8 & 0,9 & 0,8 & 0,8 & 0,8 \\
C & 34,2 & 34,2 & 34,2 & 34,2 & 34,2 & 34,2 & 34,2 & 34,2 & 34,2 & 34,2 & 34,2 \\
D & 38,2 & 38,3 & 38,3 & 38,3 & 38,2 & 38,2 & 38,2 & 38,3 & 38,3 & 38,3 & 38,2 \\
\hline
\end{tabular}

Gráfico 2 - Dados obtidos do protocolo com o MTA demonstrando o aumento da distorção geométrica na medida em que os pontos analisados se afastam do isocentro do arco estereotáxico

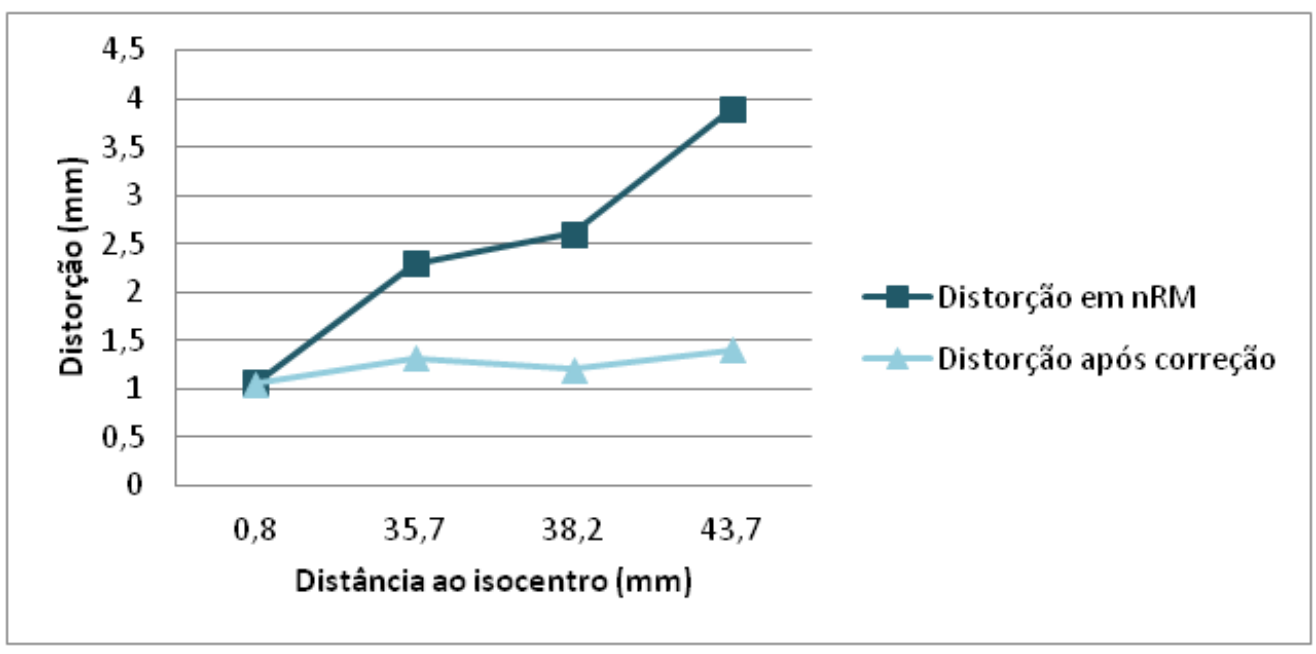


A Figura 4 ilustra uma RM normal, RM reversa e a subtração das duas imagens. Como está evidente na figura, a distorção ocorre apenas no eixo $x$ ou na fase de leitura.
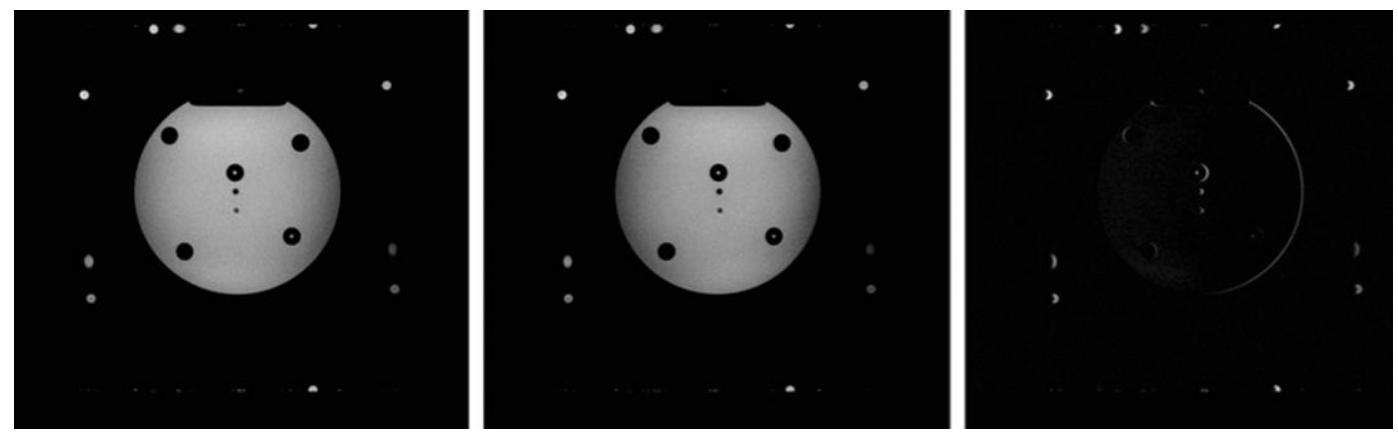

Figura 4 - Aquisição nRM (a), rRM (b) e subtração das imagens demonstrando a distorção geométrica no eixo do gradiente de leitura

\subsection{Análise da Distorção e Correção em Doentes}

Dos 20 doentes selecionados para a análise, um foi excluído, pois não foi possível identificar pontos confiáveis entre a TC, RM e rRM. O Quadro 1 demonstra as características demográficas da população selecionada. 


\section{Quadro 1- Características demográficas de cada doente assim como as condições que determinaram o uso de estereotaxia nesses doentes}

\begin{tabular}{|c|c|c|c|c|}
\hline Idade & Sexo & Diagnóstico & $\begin{array}{l}\text { Presença } \\
\text { de próteses }\end{array}$ & Procedimento \\
\hline 50 & M & $\begin{array}{l}\text { Tremor de Holmes (quadro inflamatório por } \\
\text { neurocisticercose) }\end{array}$ & DVP & $\begin{array}{l}\text { Campotomia de } \\
\text { Forel }\end{array}$ \\
\hline 67 & M & Doença de Parkinson & - & Palidotomia \\
\hline 53 & $\mathrm{~F}$ & Doença desmielinizante aguda & - & $\begin{array}{l}\text { Biópsia } \\
\text { estereotáctica }\end{array}$ \\
\hline 70 & $\mathrm{~F}$ & Glioma de baixo grau & - & $\begin{array}{l}\text { Biópsia } \\
\text { estereotáctica }\end{array}$ \\
\hline 33 & M & Esclerose múltipla (tremor intencional) & - & $\begin{array}{l}\text { Campotomia de } \\
\text { Forel }\end{array}$ \\
\hline 64 & M & Doença de Parkinson & - & Palidotomia \\
\hline 61 & M & Lesão talâmica $\mathrm{A} / \mathrm{E}$ & - & $\begin{array}{l}\text { Biópsia } \\
\text { estereotáctica }\end{array}$ \\
\hline 41 & M & Glioma de baixo grau & - & $\begin{array}{l}\text { Biópsia } \\
\text { estereotáctica }\end{array}$ \\
\hline 57 & $\mathrm{~F}$ & Lesão frontoparietal A/E & - & $\begin{array}{l}\text { Biópsia } \\
\text { estereotáctica }\end{array}$ \\
\hline 58 & M & Lesão talâmica $\mathrm{A} / \mathrm{E}$ & - & $\begin{array}{l}\text { Biópsia } \\
\text { estereotáctica }\end{array}$ \\
\hline 37 & $\mathrm{~F}$ & Vasculite & - & $\begin{array}{l}\text { Biópsia } \\
\text { estereotáctica }\end{array}$ \\
\hline 54 & $\mathrm{~F}$ & Lesão temporal A/E & - & $\begin{array}{l}\text { Biópsia } \\
\text { estereotáctica }\end{array}$ \\
\hline 45 & $\mathrm{~F}$ & Lesão parietal $A / E$ & - & $\begin{array}{l}\text { Biópsia } \\
\text { estereotáctica }\end{array}$ \\
\hline 55 & M & Doença de Parkinson & - & Palidotomia \\
\hline 63 & M & Lesão parieto-occipital A/E & - & $\begin{array}{l}\text { Biópsia } \\
\text { estereotáctica }\end{array}$ \\
\hline 65 & M & Lesão anular occipital A/E & - & $\begin{array}{l}\text { Biópsia } \\
\text { estereotáctica }\end{array}$ \\
\hline 16 & M & $\begin{array}{l}\text { Lesão isquêmica em gânglios da base/ } \\
\text { Distonia }\end{array}$ & - & $\begin{array}{l}\text { Campotomia de } \\
\text { Forel }\end{array}$ \\
\hline 36 & $\mathrm{~F}$ & Esclerose Múltipla/ Tremor & - & $\begin{array}{l}\text { Campotomia de } \\
\text { Forel }\end{array}$ \\
\hline 25 & M & Lesão em Tronco Encefálico A/E & - & $\begin{array}{l}\text { Biópsia } \\
\text { estereotáctica }\end{array}$ \\
\hline 20 & M & Distonia & - & $\begin{array}{l}\text { Campotomia de } \\
\text { Forel }\end{array}$ \\
\hline
\end{tabular}

Nota-se uma distorção mínima de 0 mm e máxima de 5,6 mm. Após a correção a distorção mínima e máxima encontrada foi de 0 e $3,5 \mathrm{~mm}$ respectivamente. Conforme demonstra a Tabela 5, não houve diferença significativa entre as coordenadas $\mathrm{x}$ na TC e $\mathrm{x}$ corrigida. 
Tabela 5 - Diferença entre as coordenadas obtidos na TC e as obtidas após a correção

\begin{tabular}{lcccccc}
\multicolumn{1}{c}{ Variáveis } & $\mathbf{n}$ & Média & $\begin{array}{c}\text { Desvio } \\
\text { padrão }\end{array}$ & Mínimo & Máximo & p \\
\hline TC & 152 & 30,12 & 17,63 & 0,00 & 70,30 & \\
CORREÇÃO & 152 & 30,02 & 17,86 & 1,30 & 72,00 & 0,379 \\
\hline
\end{tabular}




\section{Discussão}


Em 1999, os primeiros sistemas de RM de 3T não foram prontamente utilizados na prática clínica devido à qualidade insuficiente de bobinas para emissão da radiofrequência e do protocolos de execução impraticáveis. Mesmo assim, esses protocolos foram utilizados em laboratórios para obtenção de imagens cerebrais por muitos anos. Nesses experimentos restritos foram demonstradas melhores SNR, resolução parcial, temporal e espectral utilizando-se técnicas semelhantes em relação aos sistemas de 1,5T. Com os ganhos de SNR, houve um aumento concomitante da nãohomogeneidade do campo magnético. Os sistemas de $3 T$ possuem frequência de ressonância mais elevada o que resulta em maior interferência no sinal de radiofrequência produzindo distorções de maior intensidade na imagem quando comparados ao aparelhos de menor campo (Kim et al., 2014). Portanto, uma das maiores dificuldades quanto ao uso da RM de $3 T$ em procedimentos estereotácticos é um aumento da não-homogeneidade do campo magnético, que também é uma das maiores fontes de distorção de imagem (Barth et al., 2007). Além disso, a extensão da não-linearidade do gradiente de campo magnético varia consideravelmente de sistema para sistema. Portanto, tornou-se mandatório o desenvolvimento de método de correção para distorção que permitisse o uso de estereorresonância para 3T (Wang, 2004a, 2004b e 2004c; Baldwin et al., 2007). 
Diversos métodos foram propostos para correção de distorção. Como foi demonstrado por Chang (Chang e Fitzpatrick, 1992), o gradiente de phase encoding não é suscetível a não-homogeneidade do campo magnético. Alguns autores (Bendel, 1985; Wong e Rosenfeld, 1987) tentaram utilizar essa não suscetibilidade. Infelizmente, essas técnicas demandam tempos de aquisição extremamente longos, pois sacrificam a montagem dos dados em paralelo a partir da fase de frequency encoding a fim de obter a imunidade da nãohomogeneidade do campo fornecida pela phase enconding.

Outro conceito incluía o uso de mapas derivados do campo de distorção, baseados na aquisição de imagens a partir de um MTA conhecido (Lai, 1983; O'Donnell e Edelstein, 1985). Outro método inclui transformação Fourier de imagens para corrigir distorções de intensidade (Hutchison et al., 1978). A grande dificuldade na aplicação desses métodos é a falta de correção da distorção geométrica, que é o foco da neurocirurgia estereotáctica. Para suprir essa deficiência, Sekihara e Kohno (1987) propuseram um método mais completo utilizando técnica de spin warp, aplicando uma sequência de pulso com duas direções de phase encoding em um MTA uniforme, o que permitiu calcular um mapa de campo. A imagem obtida a partir do objeto foi então retificada empregando um mapa conhecido que continha informações sobre as distorções geométricas e de intensidade.

A arguição de Chang e Fitzpatrick (1992) sobre os diversos métodos de correção aponta para diversas desvantagens. O MTA não representa de maneira satisfatória os humanos ou animais cujas imagens são obtidas. Com isso, as variações no campo produzidas pela suscetibilidade magnética 
do objeto são ignoradas. Isso significa que as correções efetuadas levam em consideração apenas as distorções que não são produzidas pelo objeto em questão. Além disso, as distorções com origem em outras fontes que não o objeto podem variar com o tempo, portanto, o mapa de campo pode não ter a precisão adequada no momento da aquisição (Feig e Perlin 1986). Finalmente, se o mapa de campo for extrapolado a partir de coordenadas próximos aos fiduciais, as coordenadas distantes dos pontos fiduciais podem limitar a precisão do processo de correção.

O método aplicado no presente estudo foi desenvolvido por Chang e Fitzpatrick (1992) e foi utilizado previamente, com sucesso, em imagens estereotácticasde 1,5T (Maciunas et al., 1996). O método envolve a aquisição de duas imagens utilizando sequências de pulso idênticas, exceto para mudanças no gradiente magnético. As duas imagens distorcidas foram então combinadas para produzir uma imagem retificada. Essa técnica permite a correção de distorções geométricas nas imagens de RM realizadas de rotina com a sequência spin-echo. Para sequências de pulso de difusão multidirecional, como a echo planar imaging (EPI), outros protocolos devem ser utilizados. A razão para tanto é que cada transição entre o momento que o gradiente é ligado e desligado produz correntes eddy em algum grau. Se a corrente eddy e o seu campo magnético associado apresentam um decaimento para um valor inexpressivo entre o tempo de transição da aplicação do gradiente de campo e a leitura da imagem, uma mudança espacial-dependente na fase da imagem vai aparecer, mas sem distorção identificável. Entretanto, se o decaimento ocorrer de maneira lenta, 
de forma que o campo residual se mantenha durante a fase de leitura da imagem, o campo se comporta como um gradiente de enconding espacial extra e causará distorção na imagem. Em conclusão, a distorção a partir de correntes eddy e o gradiente de phase encoding devem ser levados em consideração nessas sequências (Clare, 1997).

Como foi demonstrado no estudo a partir do MTA nas Tabelas 2 e 3, a distorção geométrica média foi reduzida para menos que $1 \mathrm{~mm}$, o que é erro aceitável em procedimentos estreotácticos. Com a finalidade de verificar o efeito do objeto na distorção e correção, foi aplicada a mesma metodologia aos 19 doentes selecionados (Anexo B). A distorção mínima variou de $0 \mathrm{~mm}$ a 3,5 mm após a correção. A Tabela 5 demonstra que não houve diferença significativa entre a coordenada x obtida a partir da TC e a correção efetuada para essa coordenada em RM.

Entretanto, a técnica possui algumas limitações. A correção é superior no centro da imagem em comparação com as extremidades (onde a distorção atingiu 3,7 $\mathrm{mm}$ no MTA), o que tem que ser levado em consideração pelo cirurgião. Além disso, o tempo entre a aquisição da imagem normal e da imagem reversa pode adicionar outra possibilidade de distorção tendo em vista que o campo magnético não é totalmente estável. Outro problema é que sistema estereotáctico deve ser manufaturado a partir de componentes não metálicos, pois mesmo se estes não forem ferromagnéticos ainda podem adicionar imperfeições na imagem de RM. A razão para isso é que a não-homogeneidade do campo magnético induzida pelo objeto seria inaceitável. Todavia, a simplicidade da técnica permite seu 
uso rotineiro, pois dispensa a realização de cálculos complexos e demorados. Entretanto, o processo somente pode ser realizado em RM com software aberto a fim de que se possa modificar as linhas de programação da sequência de pulso para se obter a imagem reversa. Para isso, o físico de RM tem um papel chave no processo. Ele é o responsável por identificar e ajustar adequadamente as novas linhas de programação dentre milhares de linhas que compõe o programa sem modificar os outros parâmetros. Esse processo é complexo e potencialmente perigoso, pois, uma modificação inadequada pode originar erros de aquisição na imagem e dificultar sua interpretação. 


\section{ConClusões}


a) Conforme análise quantitativa realizada em imagens do MTA obtidas em RM de $3 T$, concluímos que a distorção está presente, sendo menor e praticamente desprezível quando os pontos são próximos ao isocentro da imagem, mas é significativamente maior em sua periferia. Secundariamente concluímos que o método de correção proposto neste estudo é pertinente, pois pode reduzir significativamente a distorção.

b) Concluímos que o método proposto pode ainda corrigir satisfatoriamente distorções em estudos de ressonância clinicamente aplicáveis. O uso clínico da técnica pode ser prático e eficiente a partir da automação por software do processo. Deste modo, o referido método ainda pode ser aplicado em todas as imagens de RM spin-echo obtidas. 
8 AnEXos 
Anexo A - Projeto e características do MTA para estudo da distorção geométrica

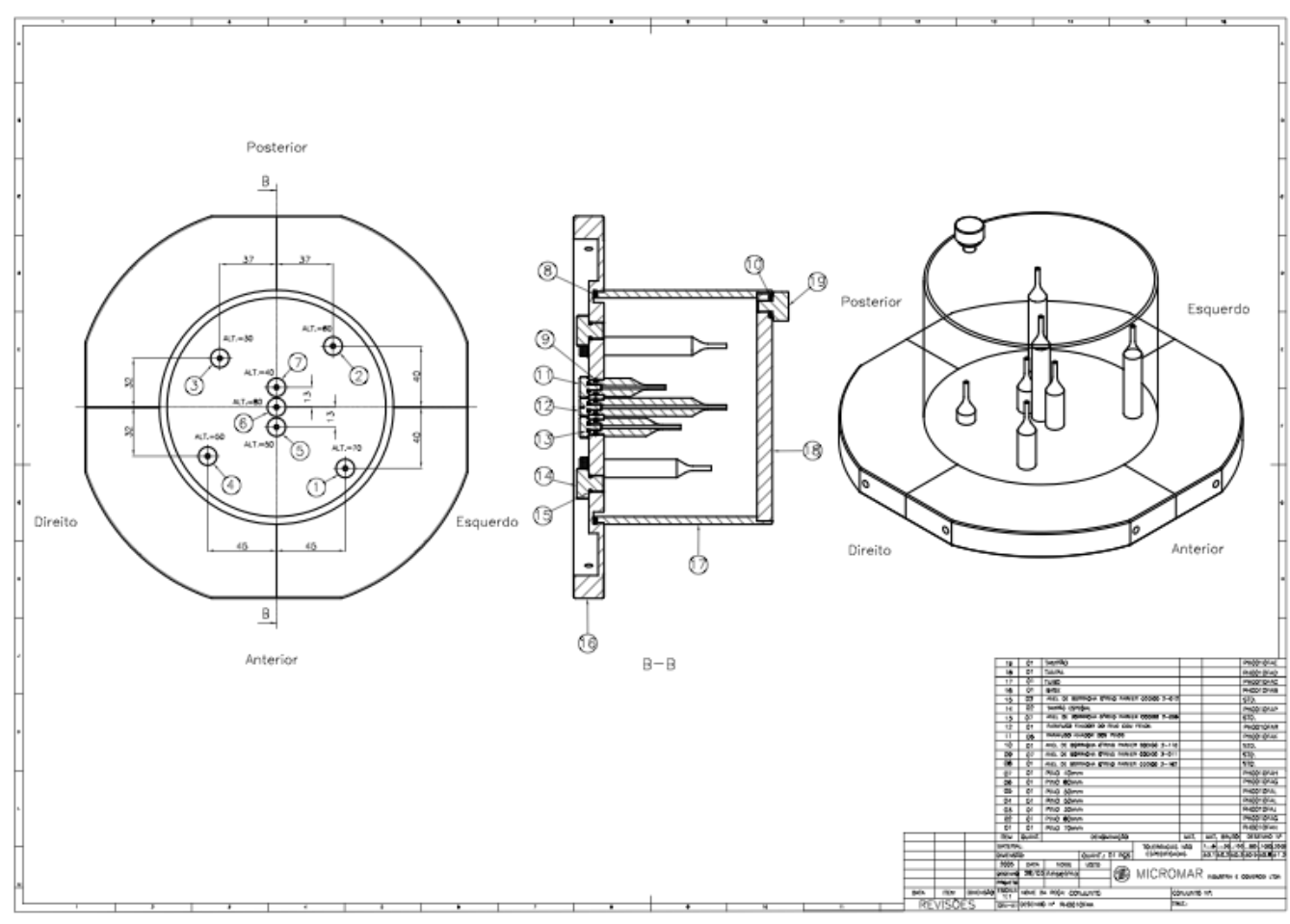


Anexo B - Pontos de coordenada $x$ obtidos (em $\mathrm{mm}$ ) para cada paciente em TC, RM e rRM. Cálculo da distorção (diferença) e coordenada $\mathrm{x}$ corrigida

\begin{tabular}{|c|c|c|c|c|c|c|}
\hline PACIENTES & PONTOS & $\mathrm{TC}$ & RM & rRM & CORREÇÃO (x corrigido) & $\begin{array}{c}\text { DIFERENÇA } \\
(\mathrm{mm})\end{array}$ \\
\hline \multicolumn{7}{|l|}{ V.A.P } \\
\hline & 1 & 7 & 5,3 & 5,8 & 5,55 & 1,45 \\
\hline & 2 & 39,9 & 37,8 & 38,7 & 38,25 & 1,65 \\
\hline & 3 & 28,1 & 30,7 & 28,9 & 29,8 & 1,7 \\
\hline & 4 & 39,9 & 41,3 & 40,5 & 40,9 & 1 \\
\hline & 5 & 25 & 22,7 & 23,1 & 22,9 & 2,1 \\
\hline & 6 & 34,4 & 33,8 & 33,3 & 33,55 & 0,85 \\
\hline & 7 & 62,5 & 60,4 & 62,7 & 61,55 & 0,95 \\
\hline & 8 & 46,1 & 46,2 & 48,4 & 47,3 & 1,2 \\
\hline \multicolumn{7}{|l|}{ T.U. } \\
\hline & 1 & 0 & 2,7 & 0 & 1,35 & 1,35 \\
\hline & 2 & 46,9 & 46,7 & 45,8 & 46,25 & 0,65 \\
\hline & 3 & 16,4 & 14,2 & 17,8 & 16 & 0,4 \\
\hline & 4 & 70,3 & 73,3 & 70,7 & 72 & 1,7 \\
\hline & 5 & 15,6 & 17,8 & 15,1 & 16,45 & 0,85 \\
\hline & 6 & 6,3 & 5,3 & 7,6 & 6,45 & 0,15 \\
\hline & 7 & 39,9 & 40,9 & 39,1 & 40 & 0,1 \\
\hline & 8 & 41,4 & 42,2 & 40,4 & 41,3 & 0,1 \\
\hline \multicolumn{7}{|l|}{ R.A.S. } \\
\hline & 1 & 6,8 & 6,3 & 4,4 & 5,35 & 1,45 \\
\hline & 2 & 2,1 & 2,2 & 0,4 & 1,3 & 0,8 \\
\hline & 3 & 45,1 & 44 & 43,6 & 43,8 & 1,3 \\
\hline & 4 & 42,4 & 43,6 & 44,9 & 44,25 & 1,85 \\
\hline & 5 & 41,7 & 39,1 & 41,3 & 40,2 & 1,5 \\
\hline & 6 & 63,6 & 64 & 65,3 & 64,65 & 1,05 \\
\hline & 7 & 49,2 & 49,3 & 49,3 & 49,3 & 0,1 \\
\hline & 8 & 52 & 51,6 & 52,9 & 52,25 & 0,25 \\
\hline \multicolumn{7}{|l|}{ T.P.N. } \\
\hline & 1 & 8 & 8,6 & 7,6 & 8,1 & 0,1 \\
\hline & 2 & 21,1 & 20,9 & 20 & 20,45 & 0,65 \\
\hline & 3 & 11,7 & 12 & 12 & 12 & 0,3 \\
\hline & 4 & 43 & 41,8 & 42,7 & 42,25 & 0,75 \\
\hline & 5 & 64,1 & 65,4 & 64,9 & 65,15 & 1,05 \\
\hline & 6 & 35,2 & 34,2 & 34,2 & 34,2 & 1 \\
\hline & 7 & 18 & 19,6 & 18,7 & 19,15 & 1,15 \\
\hline & 8 & 27,3 & 28,9 & 29,3 & 29,1 & 1,8 \\
\hline \multicolumn{7}{|l|}{ R.P.F. } \\
\hline & 1 & 27,3 & 24,4 & 24,9 & 24,65 & 2,65 \\
\hline & 2 & 21,9 & 18,7 & 19,6 & 19,15 & 2,75 \\
\hline & 3 & 10,9 & 13,8 & 12,9 & 13,35 & 2,45 \\
\hline & 4 & 32,8 & 30,7 & 30,2 & 30,45 & 2,35 \\
\hline & 5 & 38,3 & 36,4 & 37,3 & 36,85 & 1,45 \\
\hline & 6 & 61,7 & 60,4 & 61,4 & 60,9 & 0,8 \\
\hline & 7 & 45,3 & 45,3 & 46,7 & 46 & 0,7 \\
\hline & 8 & 6,3 & 5,3 & 5,4 & 5,35 & 0,95 \\
\hline \multicolumn{7}{|l|}{ N.F.A.M. } \\
\hline & 1 & 8,6 & 8,5 & 6,7 & 7,6 & 1 \\
\hline & 2 & 7,8 & 6,7 & 8,9 & 7,8 & 0 \\
\hline & 3 & 10,2 & 9,3 & 11,1 & 10,2 & 0 \\
\hline & 4 & 47,7 & 48,4 & 45,4 & 46,9 & 0,8 \\
\hline & 5 & 44,5 & 43,6 & 45,3 & 44,45 & 0,05 \\
\hline & 6 & 5,5 & 4,9 & 6,7 & 5,8 & 0,3 \\
\hline & 7 & 11,7 & 9,3 & 11,6 & 10,45 & 1,25 \\
\hline & 8 & 14,8 & 14,2 & 15,6 & 14,9 & 0,1 \\
\hline \multicolumn{7}{|l|}{ M.G.D. } \\
\hline & 1 & 38,7 & 39,1 & 36 & 37,55 & 1,15 \\
\hline & 2 & 32,7 & 32,9 & 28,9 & 30,9 & 1,8 \\
\hline & 3 & 25,5 & 25,8 & 20,9 & 23,35 & 2,15 \\
\hline & 4 & 10,4 & 12,9 & 9,3 & 11,1 & 0,7 \\
\hline & 5 & 14,7 & 13,5 & 10,2 & 11,85 & 2,85 \\
\hline & 6 & 12 & 12,5 & 16 & 14,25 & 2,25 \\
\hline & 7 & 34,3 & 33,8 & 36,9 & 35,35 & 1,05 \\
\hline & 8 & 24 & 25,5 & 28,9 & 27,2 & 3,2 \\
\hline
\end{tabular}




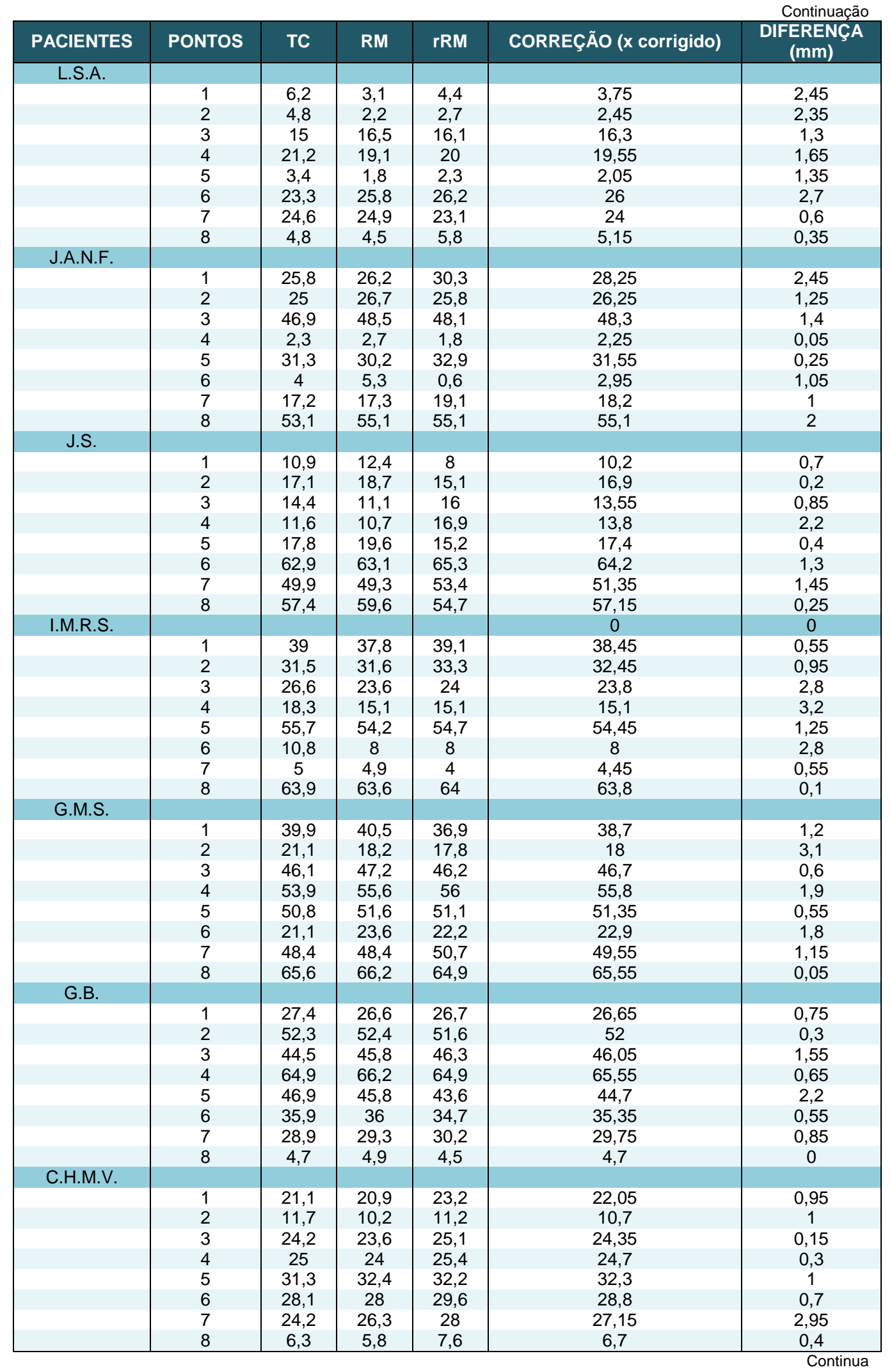




\begin{tabular}{|c|c|c|c|c|c|c|}
\hline PACIENTES & PONTOS & TC & $\mathbf{R M}$ & rRM & CORREÇÃO ( $x$ corrigido) & $\begin{array}{l}\text { Conclusão } \\
\text { DIFERENÇA } \\
(\mathrm{mm})\end{array}$ \\
\hline \multicolumn{7}{|l|}{ B.B.S. } \\
\hline & 1 & 10,1 & 9,9 & 7,7 & 8,8 & 1,3 \\
\hline & 2 & 22,5 & 22,7 & 24,8 & 23,75 & 1,25 \\
\hline & 3 & 35,8 & 33,8 & 35,5 & 34,65 & 1,15 \\
\hline & 4 & 34,2 & 34,5 & 35,8 & 35,15 & 0,95 \\
\hline & 5 & 30,3 & 29,5 & 31,8 & 30,65 & 0,35 \\
\hline & 6 & 28 & 27,8 & 29,5 & 28,65 & 0,65 \\
\hline & 7 & 24,1 & 25,6 & 21,1 & 23,35 & 0,75 \\
\hline & 8 & 47,4 & 45,6 & 46,1 & 45,85 & 1,55 \\
\hline \multicolumn{7}{|l|}{ A.M.P. } \\
\hline & 1 & 46,1 & 44,9 & 47,1 & 46 & 0,1 \\
\hline & 2 & 28,9 & 26,2 & 29,8 & 28 & 0,9 \\
\hline & 3 & 18 & 17,8 & 20,4 & 19,1 & 1,1 \\
\hline & 4 & 52,4 & 55,1 & 54,2 & 54,65 & 2,25 \\
\hline & 5 & 15,6 & 15,6 & 13,3 & 14,45 & 1,15 \\
\hline & 6 & 52,4 & 52,5 & 52,5 & 52,5 & 0,1 \\
\hline & 7 & 54,7 & 53,3 & 52,9 & 53,1 & 1,6 \\
\hline & 8 & 43 & 42,2 & 41,3 & 41,75 & 1,25 \\
\hline \multicolumn{7}{|l|}{ A.S.C. } \\
\hline & 1 & 3,9 & 4,9 & 3,1 & 4 & 0,1 \\
\hline & 2 & 7,8 & 8,5 & 6,2 & 7,35 & 0,45 \\
\hline & 3 & 38,3 & 37,5 & 36 & 36,75 & 1,55 \\
\hline & 4 & 55,5 & 55,8 & 54,3 & 55,05 & 0,45 \\
\hline & 5 & 36,7 & 35,2 & 34,7 & 34,95 & 1,75 \\
\hline & 6 & 23,4 & 23,6 & 22,7 & 23,15 & 0,25 \\
\hline & 7 & 53,1 & 54,3 & 55,1 & 54,7 & 1,6 \\
\hline & 8 & 30,5 & 30,7 & 32,9 & 31,8 & 1,3 \\
\hline \multicolumn{7}{|l|}{ A.A.F. } \\
\hline & 1 & 36,7 & 34,7 & 35,2 & 34,95 & 1,75 \\
\hline & 2 & 20,3 & 18,2 & 20 & 19,1 & 1,2 \\
\hline & 3 & 40,6 & 37,8 & 39,2 & 38,5 & 2,1 \\
\hline & 4 & 14,8 & 15,1 & 13,4 & 14,25 & 0,55 \\
\hline & 5 & 32 & 32,9 & 31,6 & 32,25 & 0,25 \\
\hline & 6 & 54,7 & 56,5 & 54,7 & 55,6 & 0,9 \\
\hline & 7 & 60,9 & 58,7 & 61,4 & 60,05 & 0,85 \\
\hline & 8 & 22,7 & 24,9 & 24,1 & 24,5 & 1,8 \\
\hline \multicolumn{7}{|l|}{ K.B. } \\
\hline & 1 & 28,9 & 27,7 & 29,8 & 28,75 & 0,15 \\
\hline & 2 & 41,4 & 37,3 & 38,7 & 38 & 3,4 \\
\hline & 3 & 18 & 17,4 & 19,1 & 18,25 & 0,25 \\
\hline & 4 & 13,3 & 14,1 & 16 & 15,05 & 1,75 \\
\hline & 5 & 30,5 & 30,9 & 31,1 & 31 & 0,5 \\
\hline & 6 & 25,8 & 26,7 & 25,3 & 26 & 0,2 \\
\hline & 7 & 24,2 & 25,3 & 22,7 & 24 & 0,2 \\
\hline & 8 & 56,3 & 60,9 & 58,7 & 59,8 & 3,5 \\
\hline
\end{tabular}




\section{Anexo C - Aprovação do Comitê de Ética}

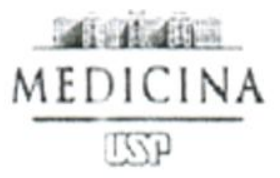

DR APROVAÇĀO 26/2009

\section{APROVAÇÃO}

O Conselho do Departamento de Radiologia aprovou "ad referendum" em 28.05.2009 o projeto de pesquisa:

Título: Análise da Ressonância Magnética como método de localização de alvos encefálicos em Neurocirurgia Funcional Estereotáxica.

Pesquisadora responsável: Dr. Manoel Jacobsen Teixeira

Pesquisadores executantes: Wagner Malagó Tavares

Responsável pelo acompanhamento: Profa. Dra. Claudia da Costa Leite

São Paulo, 28 de maio de 2009.

$$
\text { Plheinum. }
$$

Prof. Dr. Roger Chammas

Chefe do Departamento de Radiologia FMUSP 


\section{Anexo D - Termo de consentimento livre e esclarecido}

HOSPITAL DAS CLÍNICAS DA

FACULDADE DE MEDICINA DA UNIVERSIDADE DE SÃO PAULO

TERMO DE CONSENTIMENTO LIVRE E ESCLARECIDO

I - DADOS DE IDENTIFICAÇÃO DO SUJEITO DA PESQUISA OU RESPONSÁVEL LEGAL

1. NOME DO PACIENTE

DOCUMENTO DE IDENTIDADE № : SEXO : $\quad M \square F \square$

DATA DE NASCIMENTO: № APTO:

ENDEREÇO CIDADE

BAIRRO: TELEFONE: ...)

CEP:

2. RESPONSÁVEL LEGAL

NATUREZA (grau de parentesco, tutor, curador etc.)

DOCUMENTO DE IDENTIDADE : SEXO: M Ž FŽ

DATA DE NASCIMENTO.: .....................

ENDEREÇO:

№ APTO:

BAIRRO: CIDADE:

CEP: TELEFONE: DDD ...).

\section{II - DADOS SOBRE A PESQUISA CIENTÍFICA}

O presente trabalho tem por objetivo estabelecer a viabilidade do uso de Ressonância Magnética de 3 Tesla na determinação de alvos esterotácticos. O novo método não acrescentará riscos ou causará interferência no método utilizando frequentemente em nosso serviço (determinação de alvos por Tomografia Computadorizada). O único inconveniente será a realização de um exame extra (Ressonância Magnética) para que seja comparado com a Tomografia. O exame de Ressonância não adiciona riscos relacionados à radiação. 


\section{REFERÊNCIAS}


al-Rodhan NR, Kelly PJ. Pioneers of stereotatic neurosurgery. Stereotact Funct Neurosurg. 1992; 58(1-4):60-6.

Alvarez-Linera J. 3T MRI: advances in brain imaging. Eur J Radiol. 2008; $67(3): 415-26$.

Bakker CJ, Moerland MA, Bhagwandien R, Beersma R. Analysis of machinedependent and object-induced geometric distortion in 2DFT MR imaging. Magn Reson Imaging. 1992; 10(4):597-608.

Baldwin LN WK, Thomas SD, Rives R, Fallone BG. Characterization, prediction, and correction of geometric distortion in 3T MR images. Med Phys. 2007; 34(2):288-399.

Barth MM, Smith MP, Pedrosa I, Lenkinski RE, Rofsky NM. Body MR imaging at $3.0 \mathrm{~T}$ : understanding the opportunities and challenges. Radiographics. 2007; 27(5):1445-62.

Bendel P. Echo projection imaging-a method to obtain NMR images undistorted by magnetic field inhomogeneities. IEEE Trans Med Imaging. $1985 ; 4(2): 114-9$.

Bhagwandien R, van Ee R, Beersma R, Bakker CJ, Moerland MA, Lagendijk JJ. Numerical analysis of the magnetic field for arbitrary magnetic susceptibility distributions in 2D. Magn Reson Imaging. 1992; 10(2):299-313. 
Brown RA. A computerized tomography-computer graphics approach to stereotaxic localization. J Neurosurg. 1979; 50(6):715-20.

Chang $\mathrm{H}$, Fitzpatrick JM. A technique for accurate magnetic resonance imaging in the presence of field inhomogeneities. IEEE Trans Med Imaging. $1992 ; 11(3): 319-29$.

Chen L, Price RA, Jr., Wang L, Li J, Qin L, McNeeley S, Ma CM, Freedman GM, Pollack A. MRI-based treatment planning for radiotherapy: dosimetric verification for prostate IMRT. Int J Radiat Oncol Biol Phys. 2004; 60(2):636-47.

Cheng YC, Chen JH, Wang TT, Lin TT. A post-processing method for correction and enhancement of chemical shift images. Magn Reson Imaging. 2009; 27(10):1420-9.

Clare S. Functional MRI: Methods and Applications [Doctoral Thesis]. Nottingham: University of Nottingham; 1997.

Descartes R. Discours de la méthode. Paris: Garnier-Flammarion; 1966.

Dixon WT. Simple proton spectroscopic imaging. Radiology. 1984; 153(1):189-94.

Doran SJ, Charles-Edwards L, Reinsberg SA, Leach MO. A complete distortion correction for MR images: I. Gradient warp correction. Phys Med Biol. 2005; 50(7):1343-61.

Emami B, Sethi A, Petruzzelli GJ. Influence of MRI on target volume delineation and IMRT planning in nasopharyngeal carcinoma. Int $J$ Radiat Oncol Biol Phys. 2003; 57(2):481-8. 
Feig E GF, Perlin M. Magnetic resonance imaging with non-uniform fields. Phys Med Biol. 1986; 31(10):1091-9.

Fransson A, Andreo P, Potter R. Aspects of MR image distortions in radiotherapy treatment planning. Strahlenther Onkol. 2001; 177(2):59-73.

Gildenberg PL. The history of stereotactic neurosurgery. Neurosurg Clin N Am. 1990; 1(4):765-80.

Gruetter R, Weisdorf SA, Rajanayagan V, Terpstra M, Merkle H, Truwit CL, Garwood M, Nyberg SL, Uğurbil K. Resolution improvements in in vivo $1 \mathrm{H}$ NMR spectra with increased magnetic field strength. J Magn Reson. 1998; 135(1):260-4

Hitchcock ER, Tsukamoto Y. Physiological correlates in stereotactic spinal surgery. Acta Neurochir (Wien). 1974; Suppl 21:119-23.

Hitchcock ER. Stereotactic surgery for cerebral palsy. Nurs Times. 1978; 14; 74(50):2064-5

Hutchison JM, Sutherland RJ, Mallard JR. NMR imaging: image recovery under magnetic fields with large non-uniformities. J Phys E. 1978; 11(3):217-21.

Jezzard P, Balaban RS. Correction for geometric distortion in echo planar images from B0 field variations. Magn Reson Med. 1995; 34(1):65-73.

Kim HY, Lee SI, Jin SJ, Jin SC, Kim JS, Jeon KD. Reliability of stereotactic coordinates of 1.5-tesla and 3-tesla MRI in radiosurgery and functional neurosurgery. J Korean Neurosurg Soc. 2014; 55(3):136-41. 
Lai CM. Reconstructing NMR images from projections under inhomogeneous magnetic field and non-linear field gradients. Phys Med Biol. 1983; 28(8):925-38.

Lee YK, Bollet M, Charles-Edwards G, Flower MA, Leach MO, McNair $H$, Moore E, Rowbottom C, Webb S. Radiotherapy treatment planning of prostate cancer using magnetic resonance imaging alone. Radiother Oncol. 2003; 66(2):203-16.

Ludeke KM, Roschmann P, Tischler R. Susceptibility artefacts in NMR imaging. Magn Reson Imaging. 1985; 3(4):329-43.

Lyons AS PR. Medicine: an illustrated history. New York: Abrams; 1987.

Maciunas RJ, Fitzpatrick JM, Gadamsetty S, Maurer CR, Jr. A universal method for geometric correction of magnetic resonance images for stereotactic neurosurgery. Stereotact Funct Neurosurg. 1996; 66(1-3):137-40.

O'Donnell M, Edelstein WA. NMR imaging in the presence of magnetic field inhomogeneities and gradient field nonlinearities. Med Phys. 1985; 12(1):20-6.

Perrin E. SAC Instrument review process. Medical Outcomes Trust Bulletin. $1995 ; 3(4): 1-4$

Rosen BR, Wedeen VJ, Brady TJ. Selective saturation NMR imaging. $J$ Comput Assist Tomogr. 1984; 8(5):813-8.

Rosenthal H, Thulborn KR, Rosenthal DI, Kim SH, Rosen BR. Magnetic susceptibility effects of trabecular bone on magnetic resonance imaging of bone marrow. Invest Radiol. 1990; 25(2):173-8. 
Schad L, Lott S, Schmitt F, Sturm V, Lorenz WJ. Correction of spatial distortion in MR imaging: a prerequisite for accurate stereotaxy. J Comput Assist Tomogr. 1987; 11(3):499-505.

Schmitz BL, Aschoff AJ, Hoffmann MH, Gron G. Advantages and pitfalls in 3T MR brain imaging: a pictorial review. AJNR Am J Neuroradiol. 2005; 26(9):2229-37.

Sekihara K, Kohno H. Image restoration from nonuniform static field influence in modified echo-planar imaging. Med Phys. 1987; 14(6):1087-9.

Spielman D, Meyer C, Macovski A, Enzmann D. 1H spectroscopic imaging using a spectral-spatial excitation pulse. Magn Reson Med. 1991; 18(2):269-79.

Sumanaweera T, Glover G, Song S, Adler J, Napel S. Quantifying MRI geometric distortion in tissue. Magn Reson Med. 1994a; 31(1):40-7.

Sumanaweera TS, Adler JR, Jr., Napel S, Glover GH. Characterization of spatial distortion in magnetic resonance imaging and its implications for stereotactic surgery. Neurosurgery. 1994b;35(4):696-703.

Sumanaweera TS, Glover GH, Binford TO, Adler JR. MR susceptibility misregistration correction. IEEE Trans Med Imaging. 1993; 12(2):251-9.

Tanner SF, Finnigan DJ, Khoo VS, Mayles P, Dearnaley DP, Leach MO. Radiotherapy planning of the pelvis using distortion corrected MR images: the removal of system distortions. Phys Med Biol. 2000; 45(8):2117-32. 
Tavares WM, Tustumi F, da Costa Leite C, Fernel Gamarra L, Amaro E, Jr., Teixeira MJ, Fonoff ET. An image correction protocol to reduce distortion for 3-T stereotactic MRI. Neurosurgery. 2014; 74(1):121-6.

Ten Haken RK, Thornton AF, Jr., Sandler HM, LaVigne ML, Quint DJ, Fraass BA, Kessler ML, McShan DL. A quantitative assessment of the addition of MRI to CT-based, 3-D treatment planning of brain tumors. Radiother Oncol. 1992; 25(2):121-33.

Vaughan JT, Garwood M, Collins CM, Liu W, DelaBarre L, Adriany G, Andersen P, Merkle H, Goebel R, Smith MB, Ugurbil K. 7T vs. 4T: RF power, homogeneity, and signal-to-noise comparison in head images. Magn Reson Med. 2001; 46(1):24-30.

Viard R, Betrouni N, Vermandel M, Mordon S, Rousseau J, Vanhoutte M. Characterization and 3D correction of geometric distortion in low-field openmagnet MRI. Conf Proc IEEE Eng Med Biol Soc. 2008; 2008:3649-52.

Wang D, Doddrell DM, Cowin G. A novel phantom and method for comprehensive 3-dimensional measurement and correction of geometric distortion in magnetic resonance imaging. Magn Reson Imaging. 2004a; $22(4): 529-42$

Wang D, Strugnell W, Cowin G, Doddrell DM, Slaughter R. Geometric distortion in clinical MRI systems Part II: correction using a 3D phantom. Magn Reson Imaging. 2004b; 22(9):1223-32. 
Wang D, Strugnell W, Cowin G, Doddrell DM, Slaughter R. Geometric distortion in clinical MRI systems Part I: evaluation using a 3D phantom. Magn Reson Imaging. 2004c; 22(9):1211-21.

Wong TS, Rosenfeld D. Spin-Inversion Imaging: A Technique for NMR Imaging under Magnetic Fields with High Field Nonuniformities. IEEE Trans Med Imaging. 1987; 6(2):148-56. 
APÊNDICE 


\section{Apêndice A - Artigo publicado}

\section{An Image Correction Protocol to Reduce Distortion for 3-T Stereotactic MRI}

Wagner Malagó Tavares, MD* Francisco Tustumi, MS* Claudia da Costa Leite, MD, $\mathrm{PhD} \neq$

Lionel Fernel Gamarra, $\mathrm{PhD} \ddagger \S$ Edson Amaro Jr, MD, PhD Manoel Jacobsen Teixeira, $\mathrm{MD}, \mathrm{PhD}^{*}$

Erich Talamoni Fonoff, MD, PhD*

Division of Functional Neurosurgen, Institute of Neurology, University of Sa Paulo, Såo Paulo, Brazil; † Department of sity of Sảo Paulo, Sảo Paulo, Bra SHospital Israelita Albert Einstein, Säo Paulo, Brazil

\section{Correspondence:}

Wagner Malagó Tavares, MD Division of Functional Neurosurgery, Department of Neurology, University of Säo Paulo School of Medicine,

Ovideo Pires de Campos 785, E-mail: wagner.tavares 9 hc..́m.usp.br

Received, November 8, 2012 Published Online, September 23, 2013 .

Copyright $\odot 2013$ by the Congress of Neurological Surgeons
BACKGROUND: Image distortion limits application of direct 3-T magnetic resonance imaging for stereotactic functional neurosurgery.

OBJECTIVE: To test the application of a method to correct and curtail image distortion of 3-T magnetic resonance images.

METHODS: We used a phantom head model mounted on a platform with the dimensions and features of a stereotactic frame. The phantom was scanned within the head coil of a Philips Achieva 3T X series (Philips Medical Systems, Eindhoven, the Netherlands). For each scan, 2 images were obtained-the normal and the reversed images. We applied the inverted gradient correction protocol to produce a corrected $x, y$, and $z$ coordinates. We applied the Cronbach test or coefficient of reliability to assess the internal consistency of the data.

RESULTS: For all analyzed data, the $P$ value was $>.05$, indicating that the differences among the observers were not statistically significant. Moreover, the data rectification proved to be effective, as the average distortion after correction was $1.05 \mathrm{~mm}$. The distortion varied between $0.7 \mathrm{~mm}$ and $3.7 \mathrm{~mm}$, depending on the target location.

CONCLUSION: This study examined a rectifying technique for correcting geometric distortion encountered in magnetic resonance images related to static field inhomogeneities (resonance offsets), and the technique proved to be highly successful in producing consistently accurate stereotactic target registration. The technique is applicable to all routinely used spin-echo MRI.

KEY WORDS: Distortion, Inverted sequence magnetic resonance, Stereotactic technique

Neurosurgery 74:121-127, 2014 DO: 10.1227/NEU. $00000000000000178 \quad$ www.neurosurgery-online.com

- tereotactic neurosurgical procedures rely on a device affixed to the subject's head, which uses a Cartesian coordinate system in conjunction with an imaging method to allow the localization of any given point within the stereotactic space with millimeter precision. Given its superior tissue discrimination and the possibility of producing a variety of noninvasive structural and functional analyses of the inging (MRI) has become the most important imaging methor used in the diagnosis of neurological conditions. Soon after MRI became widely used fo diagnosis, the possibility of therapeutic applications emerged for use in stereotactic neurosurgery and radiation therapy. ${ }^{1}$ However, spatial distortion has remained one of the main difficulties i the direct application of MRI in stereotactic

ABBREVIATION: RF, radiofrequency surgery. Image distortion up to $25 \mathrm{~mm}$ can occu in the periphery of images created by $1.5-\mathrm{T}$ magnets. ${ }^{2,3}$ This magnitude of distortion is unacceptable for stereotactic applications, especially in functional procedures that require a high degree of precision. However, methods for allow the widespread use of $1.5-\mathrm{T}$ MRI in stereotactic neurosurgery and radiosurgery 4,5

The growing availability of high-strength magnets, beyond $1.5 \mathrm{~T}$, supports greater magnetic resonance image quality, and 3-T magne MRI instruments are now commonly found in mage distortion tends to be greater, furthe Despite the increasing use of high-strength magnets, methods for distortion correction in 1.5-T instruments, developed for stereotactic studies, ${ }^{4}$ have not been applied to images from distortion correction have been developed that medical centers worldwide. Although the tissue limiting their use in stereotactic procedures. 
3-T magnets. The current work tested algorithms for the correction of image distortion in 3-T MRI.

\section{PATIENTS AND METHODS}

A phantom head model (Micromar, Sáo Paulo, Brazil), consisting of an acrylic resin cylinder mounted on a platform wirh the dimensions and acrylic resin cylinder mounted on a platform with the dimensions and 3 fiducial markers was attached to the phantom frame to provide 9 points 3 fiducial markers was attached to the phantom frame to provide 9 points
for target calculation. Each fiducial marker consisted of an N-shaped for target calculation. Each fiducial marker consisted of an N-shaped
rubular silicone channel filled with a $3 \%$ boric acid solution to provide tubular silicone channel filled with a 3\% boric acid solution to provide
the best magnetic resonance (MR) signal. The Micromar Stereotactic the best magnetic resonance (MR) signal. The Micromar Stereotactic Frame System was used for imaging acquisition and stercotactic localization (Hitchoock frame modified). The Frame System is manufactured from Celeron, a material produced from phenolic resin and cotton wool. The system was nationally developed and is the most widely used in Brazil. The combination of the fiducial markers and the imaging system allowed each image slice, obtained from the phantom, to contain 3 reference points on the right/left and superior sides of the image (Figure 2). During image acquisition, the phantom was positioned image (Figure 2). During image

The sa a paric The signal in MRI comes from the interactions berween the magnetic moments of certain nudei in the object and the magnetic field generated by the imager. Because of their strong signal and abundance in living tissue, the protons of the hydrogen atom are the predominant nuclei of interest in most MRI scans. ${ }^{5.7}$ These protons are excited by a radiofrequency (RF) field oscillating at a frequency runed to match that of protons immersed in a static magnetic field of a specific magnitude $B$. In the most common imaging technique, "slice selection," a carefully controlled, a highly linear gradient, $G_{\infty}$ in the $z$ direction is impressed on the staric filed, so that only prorons in a plane perpendicular to the a ais cexperience the same value of $B$. An RF pube of a specife free $z$ axis expericne te same

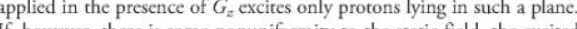
If, however, there is some nonuniformity to the static field, the excited
protons lie in a warped surface. ${ }^{5-7}$ We will let $B e(x i, y, z)$ be the

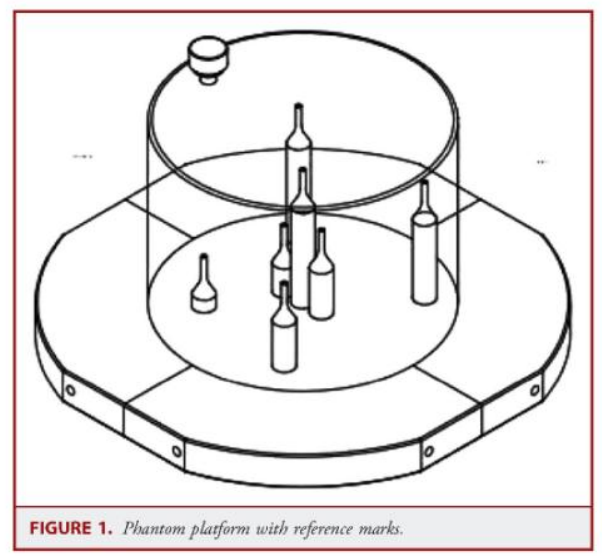

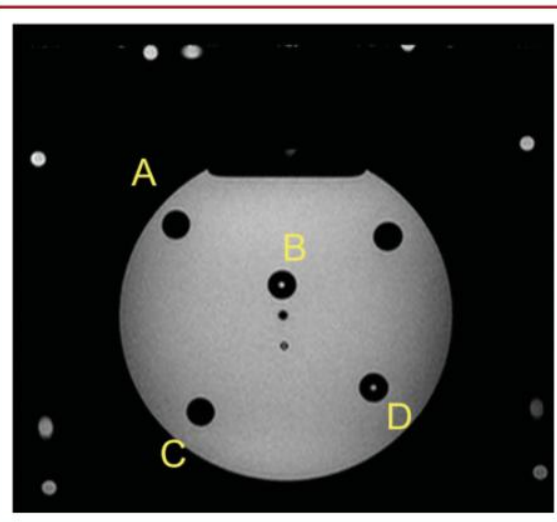

FIGURE 2. A magnetic resonance imaging slice from the phantom showing the $A, B, C$, and $D$ marks, as well as the fiducial reference points.

deviarions of the static field from nonuniformity. Be might be caused by imperfections in the main magnets of the imager or by the magnetizability of the object being imaged. To express the warp due to $B e$, we will let $x_{1}, y_{1}, z_{1}$ be the incorrect coordinates provided by the imager and $x, y, z$ be the actual coordinates of the protons. ${ }^{5-7} \mathrm{We}$ find that

$$
z_{1}=z+\frac{B_{e}(x, y, z)}{G_{z}}
$$

The derivations of this equation and the following one are provided elsewhere. ${ }^{5-7}$ These excited protons each produce a sinusoidal signal with the same phase. Their phases are deliberately dispersed by the application of a gradient $G_{y}$ in the $y$ direction of a finite time. This dispersion in the presence of a linear gradient effectively encodes the $y$ coordinate of each proton into its phase ${ }^{5-7}$ Finally, a signal is recorded during the application of a thind pratient $G_{x}$ in the $x$ direction. This sin application of a third gradient $G_{x} i n$ the $x$ direction. This signal is the sum of signals fre a liner finction of $x$ By repearing the process of slice selection with $G_{v}$ phase encoding with $G_{y}$, and readout of signal in the presence of $G_{x}$, for many different values of $G_{y}$, the imager obtains a set of signals all of which arise from the same (warped) slice of the object. ${ }^{5-7}$ A 2-dimensional Fourier transform of this signal produces a distribution of signal in $x, y$ that represents the distribution of the magnetic field $M$ of the protons. There is no distortion in the $y$ coordinate arising from $B e$, but there is distortion in $x$ :

$$
x_{1}=x+\frac{B_{e}(x, y, z)}{G_{x}}
$$

In addition to the distortion in position, there is a distortion in image intensity. If we let $i(x, y, z)$ represent the undistorted image and $i_{1}\left(x_{1}, y_{1}, z_{1}\right)$, the distorted image, then 


$$
i_{1}\left(x_{1}, y, z_{1}\right)=i(x, y, z) / J_{1}\left(x_{1}, y, z_{1}\right),
$$

where $J_{1}\left(x_{1}, y_{1}, z_{1}\right)$ is the Jacobian of the transformation from $x, y$, to $x_{\mathrm{I}}$, $y_{1}, z_{1}$, and we have used $y_{1}=y$. It can be shown that

$$
J_{1}\left(x_{1}, y, z_{1}\right)=1+\frac{1}{G_{x}} \frac{\partial B_{e}(x, y, z)}{\partial_{x}}+\frac{1}{G_{z}} \frac{\partial B_{e}(x, y, z)}{\partial_{z}} .
$$

It is possible to correct the errors in $x, 2$, and the intensity described by these equations. This procedure is called rectification. ${ }^{5-7}$ We describe 2 rectification techniques, one called image rectification, and one called point rectification. ${ }^{5-7}$ The former technique is described in detail elsewhere. ${ }^{5-7} \mathrm{~A}$ considerable simplification is possible in both rectification techniques because of the typically large value of $G_{x}$. From Equations 1,2, and 4, it can be seen that for sufficiently large $G_{s}$ we can ignore those terms involving $G_{2}$. Thus, we now have $\alpha_{1}=q$ and Equations 3 and 4 become

$$
\begin{aligned}
& i_{1}\left(x_{1}, y, z\right)=i(x, y, z) / J_{1}\left(x_{1}, y, z\right), \\
& J_{1}\left(x_{1}, y, z\right)=1+\frac{1}{G_{x}} \frac{\partial B_{e}(x, y, z)}{\partial_{x}} .
\end{aligned}
$$

For both rectification techniques, we acquire an additional image, $i$ using identical imaging parameters except for a reversal in the direction of the readout gradient. For $i_{2}$, we have

$$
\begin{gathered}
x_{2}=x-\frac{B_{e}(x, y, z)}{G_{x}}, \\
i_{2}\left(x_{2}, y, z\right)=i(x, y, z) / J_{2}\left(x_{2}, y, z\right), \\
J_{2}\left(x_{2}, y, z\right)=1-\frac{1}{G_{x}} \frac{\partial B_{e}(x, y, z)}{\partial_{x}} .
\end{gathered}
$$

Combining Equations 2 and 7, we find that

$$
x=\left(x_{1}+x_{2}\right) / 2
$$

Point rectification is based on this equation. ${ }^{5-7}$ We identify a point, such as an $\mathrm{N}$-bar cross section or a target, in each image, and we use the average of these 2 positions as the rectified point. In image rectification, we combine Equations 2 and 5 through 9 to obtain a rectified image,

$$
i(x, y, z)=\frac{2 i_{1}\left(x_{1}, y, z\right) i_{2}\left(x_{2}, y, z\right)}{i_{1}\left(x_{1}, y, z\right)+i_{2}\left(x_{2}, y, z\right)}
$$

We identify points directly on this image. ${ }^{5-7}$ However, for practical purposes, we performed only point rectification because stereotactic interventions are based in defined point coordinates.

The phantom was scanned within the head coil of a Philips Achieva 3T X series (Philips Medical Systems, Eindhoven, the Netherlands). The MR scans consisted of T1-weighted, transverse, spin-echo slices. The repetition time (TR) was $600 \mathrm{~ms}$, and the echo time (TE) was $15 \mathrm{~ms}$ the field of view was $380 \mathrm{~mm}$; $256 \times 256$ pixel array was acquired; a slice thickness of $4 \mathrm{~mm}$ with a $1-\mathrm{mm}$ gap was used. For each scan, 2 images were obtained - the normal and the reversed images. The correctio protocol was performed as previously described for the $1.5-\mathrm{T}$ system. ${ }^{5} \mathrm{~A}$ computed tomography (CT) scan was used for MR geometric accurac calculations. The CT scan images were obtained using the High Speed CT scanner (GE Medical Systems, Milwaukee, Wisconsin). The instrument was set to obtain 2 -mm axial slices, without a gap, using a $512 \times 512$ matrix, with a $0.65 \times 0.65-\mathrm{mm}$ pixel array,

To ensure internal consistency and limit possible divergence amon observers, the Cronbach and Friedman tests were applied, respectively. Eleven volunteers were selected to measure the 3 marks $(B, C$, and $D)$ that were clearly identifiable in the CT and MR (Figure 2) images. Through these measurements, the $x, y$, and $z$ coordinates for each poin were obtained. The image analysis was conducted using MSA 3.50 software (Micromar Software Assistant; Micromar).

\section{RESULTS}

Previous authors ${ }^{6}$ concluded that clinically relevant MR distortion occurs only in the laterolateral $(x)$ axis, and these conclusions were confirmed in the current study. Therefore, the statistical analysis was performed using only the $x$ axis data. To assess the internal consistency of the data, the Cronbach test or coefficient of reliability was applied (Table 1 ).

The Cronbach coefficients range from 0.000 to 1.000 . To understand these data, Perrin classified the range as follows: (a) $0.000-0.599$, unsatisfactory reliability, meaning that 1 or more volunteers had to be excluded or evaluated separately, depending on the type of study; (b) $0.600-0.699$, satisfactory reliability, implying no statistical reason to exclude a volunteer; (c) 0.700 1.000 , high reliability. ${ }^{8}$ The current data achieved a calculated Cronbach coefficient of 0.999 (highly reliable). The purpose of the Friedman test is to access differences among observers. If the $P$ value is $\leq .05$, there are differences. If $P$ value is $>.05$, there are no differences, as we have shown. We applied this test because variability among observers can be a source of error. ${ }^{3}$

Tables 2 and 3 illustrate the data obtained in the $x$ axis for the $\mathrm{CT}$ and rectified MR images. Table 4 shows raw data obtained from the observers/volunteers. The Friedman test was applied on these data to assess reproducibility and possible differences among the observers/volunteers. ${ }^{8}$ For all the analyzed data, the $P$ value was $>.05$, indicating that the differences among the observers

\begin{tabular}{|lcc|}
\hline TABLE 1. Cronbach Coefficient for Data Reliability & \\
\hline Image & $\begin{array}{c}\alpha \text { Cronbach } \\
\text { Coefficient }\end{array}$ & $\begin{array}{c}\boldsymbol{P} \\
\text { Value }\end{array}$ \\
\hline $\begin{array}{l}\text { Computed tomography } \\
\text { Normal magnetic resonance image }\end{array}$ & $>0.999$ & $<.001$ \\
$\begin{array}{l}\text { Reversed magnetic resonance } \\
\text { image }\end{array}$ & $>0.999$ & $<.001$ \\
\hline
\end{tabular}




\begin{tabular}{|c|c|c|c|}
\hline Volunteers & $n$ & Mean & Significance $(P)$ \\
\hline 1 CTX & 3 & 24.33 & \\
\hline $2 \mathrm{CTX}$ & 3 & 24.33 & \\
\hline 3 CT $x$ & 3 & 24.33 & \\
\hline $4 C T X$ & 3 & 24.67 & \\
\hline $5 C T x$ & 3 & 24.67 & .44 \\
\hline $6 C T X$ & 3 & 24.67 & \\
\hline $7 \mathrm{CTX}$ & 3 & 24.67 & \\
\hline $8 \mathrm{CTX}$ & 3 & 24.33 & \\
\hline $9 \mathrm{CTX}$ & 3 & 24.33 & \\
\hline $10 \mathrm{CT} x$ & 3 & 24.33 & \\
\hline $11 \mathrm{CT} x$ & 3 & 24.67 & \\
\hline
\end{tabular}

There was no significant variation among the individuals. $\mathrm{CT}(\mathrm{x})$, computed omography $\mathrm{x}$ coordinate data

were not statistically significant. Moreover, the data rectification proved to be effective, as the average distortion, after correction, was $1.05 \mathrm{~mm}$ (range of distortion after correction, $1.05-2.75 \mathrm{~mm}$ ). The distortion before correction varied between $0.7 \mathrm{~mm}$ and $3.7 \mathrm{~mm}$, depending on the target location. The distance of the target from the center of Cartesian coordinate system determined the level of distortions, as the theory predicts; the least distortion was encountered for point $B$ (near the image center), whereas the greatest distortion was evident for point $C$ (on the image periphery). Figure 3 illustrates normal MR, inverted MR, and the subtraction of the 2 images. As evident in the Figure 3, the distortion occurs only in the $x$ axis or the read-out phase.

\section{DISCUSSION}

In 1999, when the first 3-T MRI systems became available, they were not readily used because of poor RF coil design and

\begin{tabular}{|c|c|c|c|}
\hline Volunteers & $n$ & Mean & Significance $(P$ \\
\hline $1 \mathrm{MR} x$ & 3 & 25.20 & \\
\hline $2 \operatorname{MR} x$ & 3 & 25.23 & \\
\hline $3 \mathrm{MR} x$ & 3 & 25.37 & \\
\hline $4 \mathrm{MR} x$ & 3 & 25.22 & \\
\hline $5 \mathrm{MR} x$ & 3 & 25.20 & \\
\hline $6 \mathrm{MR} x$ & 3 & 25.20 & .152 \\
\hline $7 \mathrm{MR} x$ & 3 & 25.20 & \\
\hline $8 \mathrm{MR} x$ & 3 & 25.23 & \\
\hline $9 \mathrm{MR} x$ & 3 & 25.22 & \\
\hline $10 \mathrm{MR} x$ & 3 & 25.22 & \\
\hline $11 \mathrm{MR} x$ & 3 & 25.20 & \\
\hline
\end{tabular}

There was no significant error among the volunteers selecting the same 3 points. impractical protocols. Nevertheless, they were used in laboratories and for brain imaging for many years. However, in those restricted applications, demonstrated improvements in the signal-to-noise ratio, partial and temporal resolution, and spectral resolution were achieved using similar techniques as for the $1.5-\mathrm{T}$ systems. However, with the signal-to-noise ratio gains, there was an accompanying increase in magnetic field inhomogeneity. The 3-T system's higher resonance frequency results in an augmented interference in the RF signal that produces specious intensity variations across the image. Therefore, one of the major shortcomings of a 3-T system is the increased RF field inhomogeneity, which is also one of the major sources of image distortion. ${ }^{9}$ Additionally, the extension of the gradient field nonlinearity varies considerably from system to system. Therefore, the development of a method for distortion correction is mandatory to enable 3-T MRI stereotaxy. ${ }^{10,11}$ However, one must keep in mind the different nature of each type of distortion and the influence on each $x, y, z$ coordinate (ie, static field inhomogeneity vs gradient field nonlinearity). The first is related to resonance offsets (chemical shifts and magnetic field inhomogeneities), and it mainly affects the read-out phase. The last is produced by nonlinear electric currents that pass through the orthogonal coils. Gradient field nonlinearities produce variable types of distortion, namely, barrel aberration (present in 2- and 3-dimensional MRI) and the potato chip and bow tie effect (the last 2 only present in 2-dimensional MRI). Currently, all manufacturers have provided some form of software corrections for 2-dimensional MRI. However, this may not be universally available for 3-dimensional MRI.

Several methods have been proposed for distortion correction. As demonstrated by Chang and Fitzpatrick, ${ }^{6}$ phase encoding is insensitive to field inhomogeneity. Some authors ${ }^{12,13}$ have tried to take advantage of this insensitivity. Regrettably, these techniques demand long image acquisition times because they techniques demand long image acquisition times because they
sacrifice the parallel data assemblages from the frequency encoding to derive the immunity from field inhomogeneity provided by the phase encoding.

Another concept includes the use of distortion field-based mapping. Such methods use the creation of distortion maps based on image acquisitions from a known phantom shape. ${ }^{14,15}$ Yet another method includes Fourier transformation of the images to correct intensity distortions. ${ }^{16}$ However, a major hindrance of these methods is the lack of geometric distortion correction, which is the main concern in stereotactic neurosurgery. Sekihara et $\mathrm{al}^{17,18}$ proposed a more comprehensive method using a spinwarp technique. By applying a pulse sequence with 2-phase encoding directions in a uniform phantom, they were able to calculate a field map. The image obtained from the object was then rectified by using a known map to account for the geometric and intensity distortions.

As Chang and Fitzpatrick ${ }^{6}$ pointed out, the distortion correction methods described have several disadvantages. The phantom cannot satisfactorily represent the human or animal to be imaged; hence, the variations in the field produced by the 


\begin{tabular}{|c|c|c|c|c|c|c|c|c|c|c|c|}
\hline Volunteers & 1 & 2 & 3 & 4 & 5 & 6 & 7 & 8 & 9 & 10 & 11 \\
\hline \multicolumn{12}{|l|}{$\mathrm{CT}(\mathrm{x})$} \\
\hline$B$ & 0.1 & 0.1 & 0.1 & 0.1 & 0.1 & 0.1 & 0.1 & 0.1 & 0.1 & 0.1 & 0.1 \\
\hline c & 36.3 & 36.3 & 36.3 & 36.3 & 36.3 & 36.3 & 36.3 & 36.3 & 36.3 & 36.3 & 36.3 \\
\hline D & 36.5 & 36.5 & 36.5 & 37.5 & 37.5 & 37.5 & 37.5 & 36.5 & 36.5 & 36.5 & 37.5 \\
\hline \multicolumn{12}{|l|}{ MR $(x)$} \\
\hline B & 1.5 & 1.5 & 1.5 & 1.5 & 1.5 & 1.5 & 1.5 & 1.5 & 1.5 & 1.5 & 1.5 \\
\hline c & 34.1 & 34.1 & 35 & 34.1 & 34.1 & 34.1 & 34.1 & 34.1 & 34.1 & 34.1 & 34.1 \\
\hline D & 40.2 & 40.2 & 40.2 & 40.2 & 40.2 & 40.2 & 40.2 & 40.2 & 40.2 & 40.2 & 40.2 \\
\hline \multicolumn{12}{|l|}{$\operatorname{rMR}(x)$} \\
\hline B & 0.8 & 0.9 & 0.8 & 0.8 & 0.8 & 0.8 & 0.8 & 0.9 & 0.8 & 0.8 & 0.8 \\
\hline c & 34.2 & 34.2 & 34.2 & 34.2 & 34.2 & 34.2 & 34.2 & 34.2 & 34.2 & 34.2 & 34.2 \\
\hline D & 38.2 & 38.3 & 38.3 & 38.3 & 38.2 & 38.2 & 38.2 & 38.3 & 38.3 & 38.3 & 38.2 \\
\hline
\end{tabular}

$\mathrm{CT}(\mathrm{x})$, computed tomography $\mathrm{x}$ coordinate data; $\mathrm{MR}(\mathrm{x})$, magnetic resonance $\mathrm{x}$ coordinate data; $r \mathrm{MR}(\mathrm{x})$, reverse magnetic resonance $\mathrm{x}$ coordinate data

magnetic susceptibility of the object are ignored. This means that the correction compensates only for distortions other than those produced by the object being imaged. In addition, the distortions from sources other than the object may vary with time; thus, the field map may not be accurate at the time of image acquisition. ${ }^{19}$ Finally, if the field map is extrapolated from coordinates near fiducial sites, the coordinates away from the fiducial may limit the precision of the correction process.

The method applied in this study was the one developed by Chang and Fitzpatrick ${ }^{6}$ and has been previously applied, successfully, in stereotactic $1.5-\mathrm{T}$ MR images. ${ }^{5}$ The method involves the acquisition of 2 images using identical pulse sequences, except for changes in the magnetic gradients. The 2 distorted images are then combined to produce a rectified image. This technique corrects the geometric distortions in routinely used spin-echo MR images caused by static field inhomogeneity. For pulse multidirectional diffusion sequences such as echo planar imaging, different protocols have to be applied. The reason is that each on and off field gradient transition produces eddy currents to some degree. If the eddy current (and its associated magnetic field) decays to an inconsequential value between the time of the applied field gradient transition and the image readout, a spatially dependent change in image phase will result with no discernible distortion. However, when the eddy current decays slowly, so that a residual field remains during the image readout, the field behaves like an additional spatial encoding gradient and causes distortion of the image. In conclusion, the distortion from eddy currents and phase encoding gradient $(G y)$ has to be taken into account on those sequences.

As demonstrated in Tables 2 and 3, the mean geometric distortion was reduced to less than $1 \mathrm{~mm}$, which is an acceptable stereotactic error. However, the technique has some limitations. The correction remains greater at the center of the image than at the extremities (where the distortion can reach $3.7 \mathrm{~mm}$ ), which has to be taken into account by the surgeon. Moreover, the time between MR and reversed MR slice acquisition may add error
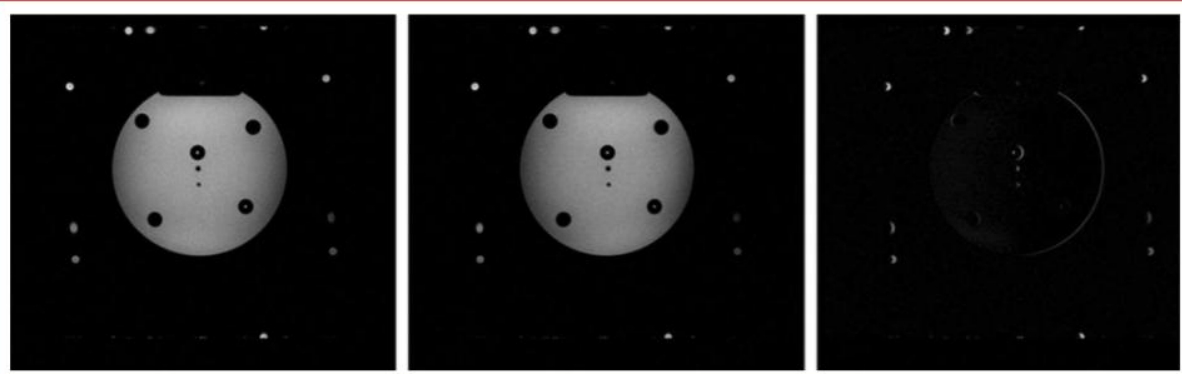

FIGURE 3. Normal image, reversed image and the resulted image subtraction between normal and reversed magnetic resonance images (right, center, and left, respectively). The shadow on the image subraction shous the geometric distortion occurring only on the $\mathrm{x}$ axis. Note that the greatset distortion occues on the image periphery. 
TAVARES ET AL

because the magnetic field is not perfectly stable. Furthermore, the stereotactic frame system has to be manufactured from nonmetal components. The reason is that the magnetic field inhomogeneities related to object-induced distortion would be unacceptable. Nevertheless, the simplicity of the technique makes it applicable to any situation without the need for complex or time-consuming calculations after the pulse sequence has been setup to obtain a reversed image, which, however, can only be done in open software MRI devices. Moreover, MR physicists have a pivotal role in the process because they are responsible for finding and adjusting, among thousands of program lines in the MR software source code, the specific MR program line that can reverse the gradient without changing any other parameter. Additionally, the MR physicist's presence in the entire process is crucial for the multidisciplinary team to understand and adjust the distortions observed.

\section{CONCLUSION}

The development of 3-T MRI instruments enabled the generation of higher quality images, but they are also subject to greater distortion, limiting their utility for stereotactic procedures. This study examined a rectifying technique for correcting geometric distortions encountered in the MR images, and the technique proved to be highly successful in producing consistently accurate stereotactic target registration. The technique is universally applicable to all routinely used spin-echo MR images and corrects for geometric distortion accountable by static field inhomogeneity. The image quality was also found to be preserved throughout the rectification process. Clinical use can be practical and efficient, with automated rectification rapidly producing images for stereotactic procedures.

\section{Disclosure}

The authors have no personal financial or institutional interest in any of the drugs, materials, or devices described in this article.

\section{REFERENCES}

1. Leksell L, Leksell D, Schwebel J. Stereotaxis and nuclear magnetic resonance, J Nearol Nearosuarg Pyychiatry. 1985; 48(1):14-18. distortion in 3D MR images. Proc SPIE, 2001;4322:1110-1120.
dite 3. Wang D, Doddrell DM, Cowin G. A novel phantom and method for
comprehensive 3-dimensional measurement and correction of geometric distortion in magnetic resonance imaging. Magn Reson Imaging. 2004; 22(4):529-542.
Maurer CR Jr, Aboutanos GB, Dawant BM, et al. Effect of geometrical dist . Maurer CR Jr, Aboutanos GB, Dawant BM, et al. Effect of geometrical distortion
correction in MR on image registration accuracy. / Comput Assist Tomogr. 1996;20 (4):666-679.

5. Maciunas RJ, Fizzpatrick JM, Gadamsetty S, Maurer CR Jr. A universal method for geometric conrection of magnetic resonance images for stereotactic neurosurgery. Stereotati Finnt Neurosurg. 1996;66(1-3):137-140.

Chang H, Fitzparrick JM. A technique for accurate magnetic resonance imaging in the presence of field inhomogeneities. IEEE Tnans Med Imaging. 1992;11(3):319-329. 5ong SF, Maciunas R Rectilication of distortion in MRR for Stereotaxy. In: Proceeding 8. Perrin E. SAC instrument review process. Med Outcomes Trust Bull. 1995;3(4) 9. Barth MM, Smith MP, Pedrosa I, Lenkinski RE, Rofksy NM. Body MR imaging
at $3.0 \mathrm{~T}$ : understanding the opportunities and challenges. Radiographics. 2007;27 (5):1445-1462; discussion 1462-1444.
(14)

0. Wang D, Strugnell W, Cowin G, Doddrell DM, Slaughter R. Geometric distortion in clinical MRI systems Part Is evaluation using a 3D phantom. Mage Reson Imaging. 2004;22(9):1211-1221.

11. Baldwin LN, Wachowizz K, Thomas SD, Rives R, Fallone BG. Characterization, prediction, and correction of geometric distortion in 3T MR images. Med Phyo. 007;34(2):288-399.

12. Bendel P. Echo projection imaging-a method to obtain NMR images undistorted by magnetic field inhomogeneities. IEEE Trans Med Imaging. 1985;4(2):114-119. 13. Wong TS, Rosenfeld D. Spin-inversion imaging: a technique for NMR imaging

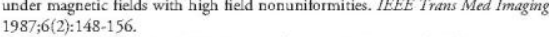

14. Lai CM. Reconstructing NMR images from projections under inhomogeneous O'Donnell M, Edelstein WA. NMR imaging in the presence of magnetic fieth inhomogeneities and gradient field nonlinearities. Med Phys. 1985;12(1):20-26. 6. Hutchison JM, Sutherland RJ, Mallard IR. NMR imaging: image recovery under magnetic fields with large non-uniformities. J Phys E. 1978;11(3):217-221. Sekihara $\mathrm{K}$, Kohno $\mathrm{H}$. Image restoration from nonuniform static field influence in modified echo-planar imaging. Med Phys. 1987;14(6):1087-1089.

8. Sekihara K, Matsui S, Kohno H. NMR imaging for magnets with large nonuniformities. IEEE Trans Med Imaging. 1985;4(4):193-199.

Feig E, Greenleaf F, Perlin M. Magnetic resonance imaging with non-uniform . Clare S. Functional MRI: Methods and Applications. Nottingham, England:
University of Nottingham; 1997.

\section{Acknowledgments}

The authors thank for the crucial support and work provided by Gilmar Gomes Lopes da Silva, MR nurse; Ricardo da Silva Nunes, MR biomedician; and Maria García Otaduy, MR physicist.

\section{COMMENTS}

n this paper, the authors describe a method to correct the distortion for n this paper, the authors describe a method to correct the distortion for
images acquired with a 3-T MRI. Accounting for distortion is particularly important in functional neurosurgery to ensure the accurate placement of intracranial electrodes. Novel deep brain stimulation targets that are located farther away from the center of the brain are likely to be even more affected by distortion. An algorithm to correct distortion of 3-T MR images is therefore timely. The technique described by the author requires modifying some component of the MRI software to allow the acquisition of a reversed image along with the true image. The reversed image is created using the inverse of the magnetic gradient used for the true image. Taking advantage of the otherwise mathematical equivalence of the 2 images, a rectification of the distortion is obtained by averaging the 2 images, a rectication posich o phantom head, (n) require further verification in humans to determine whether the targeting accuracy is truly improved.

Jean-Philippe Langevin Los Angeles, California

A s the quality of MRI improves, MRI-guided and MRI-verified deep brain stimulation, without the use of physiological recording or dinical testing, is increasing in popularity. First used in a number of European centers, ${ }^{1-6}$ this approach is also starting to gain traction in the United States. ${ }^{7,8}$ 
Therefore, this paper addresses a timely and important subject in stereotactic functional neurosurgery. Reducing image distortion is essential for accurate surgical planning to benefit from the improved tissue contrast offered by the higher field strength of 3-T MR scanners. ${ }^{9,10}$ The point rectification technique described requires a second acquisition of each MR image, identical except for a reversed read-out gradient. ${ }^{11}$ Point locations are identified separately on the forward and reverse images with the midpoint used as the corrected coordinate. By applying this technique in a phantom, the authors demonstrate the feasibility and reproducibility of the method and show a reduction in the range of point distortions after rectification by comparison with a CT reference.

MRI distortion is caused by errors between the theoretical and actual magnetic field. Distortion correction requires an understanding of the magnetic field. Distortion correction requires an understanding of the
different origins of these errors. The method described here corrects for different origins of these errors. The method described here corrects for static field errors, largely caused by magnetic susceptibility of the patient's tissues. ${ }^{12}$ In most sequences, these occur only along the readout direction and are precisely reversed by readout gradient reversal. However, as the authors note, other errors will not be eliminated by this approach. Spatial gradient nonlinearity causes distortions that depend only on position and will not change sign with read-out gradient polarity. ${ }^{12-14}$ Some MRI systems offer independent correction for this. Other MRI sequences (notably echo planar imaging) demonstrate different, more complex distortion effects ${ }^{15-17}$ The complexity of this sinuation and the potential disto for serial cortection of diferent entose collaboration between surgical, scientific, and radiological experts in

The technique used here has the potential for wide applicability. Many MRI scanners allow user control of read-out polarity, and rectified coordinates can then be calculated without specialist software. Point rectification is thus much more easily applied than full image-based correction, which would require additional image post-processing. Development for human application at 3-T will require assessment of target point reproducibility in brain tissue to confirm that a net increase in stereotactic accuracy can be achieved.

Mark White Ludvic Zrinzo London, United Kingdom
1. Vayssiere $\mathrm{N}$, Hemm S, Zanca M, et al. Magnetic resonance imaging stereotactic target localization for deep brain stimulation in dystonic children. J Neurosurerg arget localization for
000;93(5):784-790.

2. Hariz MI, Krack P, Melvill R, et al. A quick and universal method for stereotactic visualization of the subthalamic nucleus before and after implantation of deep brai stimulation electrodes. Sterrotactic Funct Nearosirg. 2003;80(1-4):96-101,

3. Patel NK, Plaha P, Gill SS. Magnetic resonance imaging-directed method for functional neurosurgery using implantable guide tubes. Neurrosurgery. 2007;61( suppl 2):358-365; discussion p365-366.

4. Foltynie T, Zrinzo L, Martinez-Torres I, et a.. MRI-guided STN DBS in Parkinson's disease without microelectrode recording: efficacy and safery. J Neture Nearosing fochiatr. 2011,02(4).558-363.

5. Zrinzo L, Foltynie T, Limousin P, Hariz M. Image-verified deep brain stimulation (12): 1585-1586. cost with no apparent

Coubes P. Vaysiere N, Fertit el H, et at. Deep brin stimulation for dystoniSurgical technique. Stereotactic Funct Neurosurg. 2002; 78(3-4):183-191.

Start PA, Martin AI, Ostrem IL, Talke P, Levesque N, Larson PS, Subthalamic nucleus deep brain stimulator placement using high-field interventional magnetic resonance imaging and a skull-mounted aiming device: technique and application accuracy. I Nelerosutry. 2010;112(3):479-490.

Gross RE, McDougal ME. Technological advances in the surgical treatment of movement disorders. Curr Neurol Neurasci Rep. 2013;13(8):371.

Slavin KV, Thulborn KR, Wess C, Nersesyan H. Direct visualization of the humaa

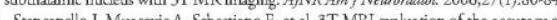
Stancand J, MuacevicA, Sebastiano F, et al $5 T$ MRR evaluation of the accuracy of presence of field it Sumanaweera TS, Adler JR, Napel S, Glover GH. Chancterization of optis distortion in magnetic resonance imaging and its implications for stereotactic surgery. Neurosurgery, 1994; 35(4):696-703; discussion 703-704.

3. Janke A, Zhao H, Cowin GI, Galloway Gl, Doddrell DM. Use of spherical armonic deconvolution methods to compensate for nonlinear gradient effects on MRI images. Magn Reson Med. 2004;52(1):115-122.

4. Doran SJ, Charles-Edwards L, Reinsberg SA, Leach MO. A complete distortio orrection for MR images: I. Gradient warp correction. Phys Med Biol 2005;50(7)

15. Hutton C, Bork A, Josephs O, Deichmann R, Astburnet J, Turner R. Image distortio cortection in AMRI: a quartitative evaluation. Neuvolmage. 2002;16(1):217-240. Embleton KV, H

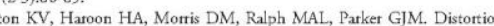
correction for diffusion-weighted MRI tractography and AMRI in the temponal lobes. Hiom Brain Mapp. 2010;31(10):1570-1587. 